\title{
مساهمة شركات رأس المال المخاطر في تمويل المؤسسات الصغيرة والمتوسطة \\ حالة الولايات المتحدة الأمريكية في الفترة (1980-2015)
}

$$
\begin{aligned}
& \text { أ. بلعابد سيف الإسلام النوي } \\
& \text { أ.د. قدي عبد المجيد } \\
& \text { كلية العلوم الاقتصادية } \\
& \text { مخبر العولمة والسياسات الاقتصادية } \\
& \text { جامعة الجز ائر } 3
\end{aligned}
$$

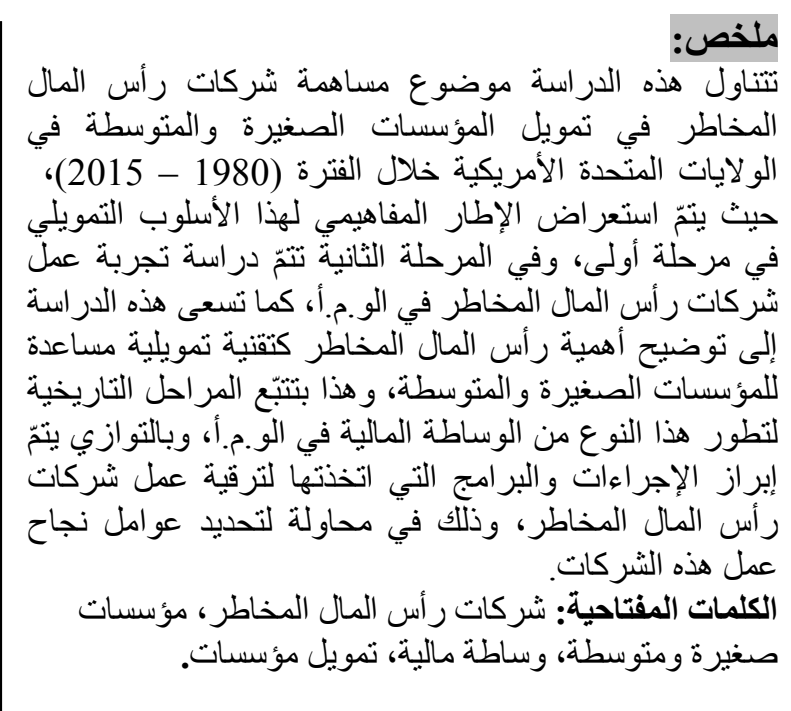

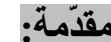

يحظى قطاع المؤسسات الصغيرة

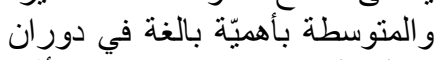

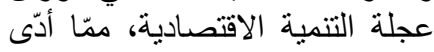

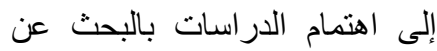
كيفية ضرورة تنمينه وتطويره؛ بالبت

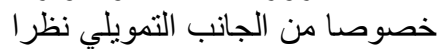

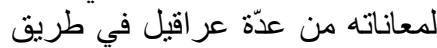
حصوله على الائتمان البنكي.

وبغرض التخفيف من حدّة العراقيل التيل

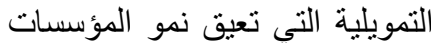

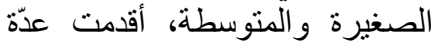
دول إلى ابتكار أساليب تمويلية النية تنتاسب المؤسسات، حيث برز أسلوب

\begin{abstract}
:
This study sheds light on venture capital firms participation in small and medium enterprises' finance in the United States of America during the period (1980-2015), it consists of the conceptual framework of this financing method in the first phase, and in the second phase, it has been studied a work experience of the venture capital firms in the U.S.A, The study leads to show the importance of using the venture capital as a financing technique for helping the small and medium enterprises, and follow the historical stages of this kind of the Financial intermediation in U.S.A, In parallel was highlighted the procedures and programs undertaken by this last to upgrade the work of venture capital firms, In an attempt to determine the success factors of the work of these companies.
\end{abstract}

Key words : Venture capital firms, small and medium enterprises, Financial intermediation, Enterprisesfinance. 
التمويل وفق رأس المال المخاطر كأداة لتجاوز بعض هذه الإثكالات. فهو عبارة عن أسلوب تمويلي

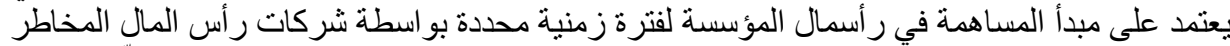

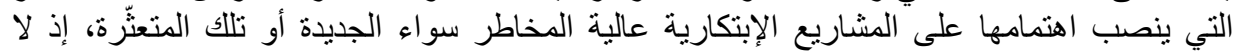

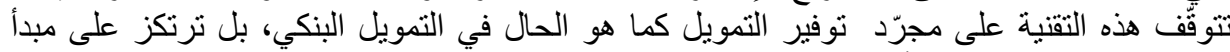

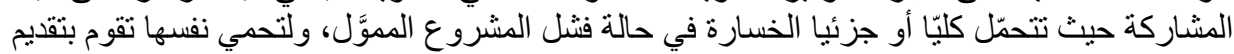

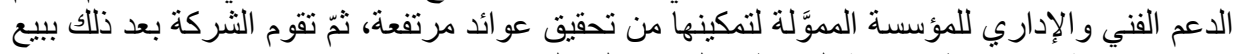

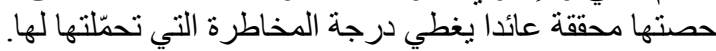

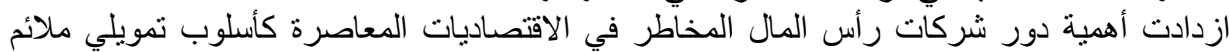

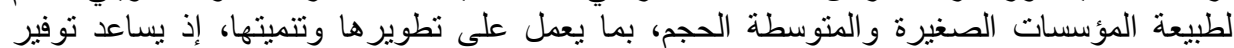

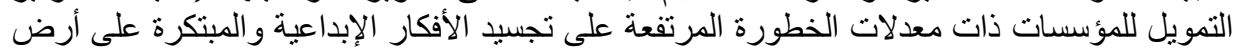

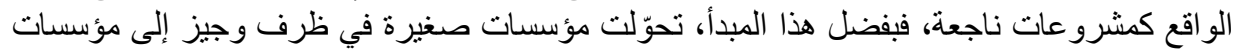

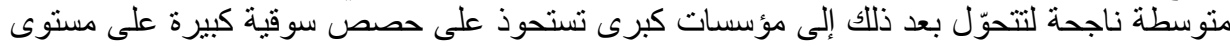

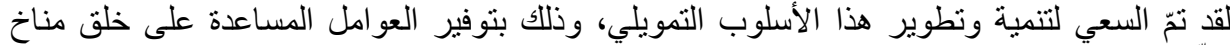

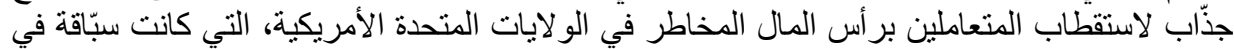

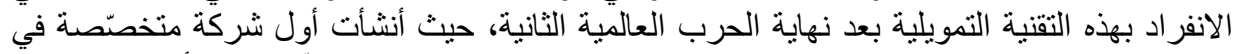

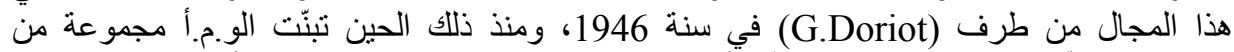
الإجراءات مكّنتها من اعتلاء "المرتبة الأولى عالميا في حجم الاستثمارات في رأس المال المال المخاطر

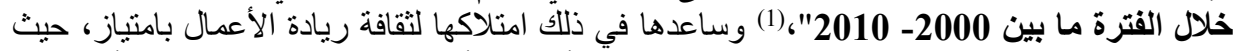

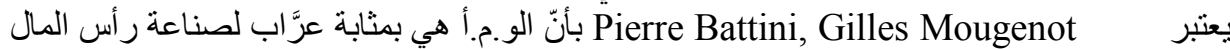
المخاطر على المستوى العالمي.

ونتيجة لهذه المعاينة تظهر ألحاجة إلى إبراز المساهمة التمويلية التي تؤديها شركات رأس المال

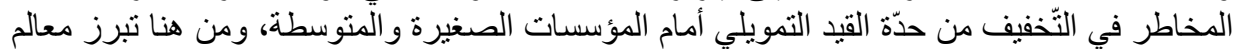
إنكالية البحث التي يمكن صياغتها على النى النحو التالي:

إلى أي حذ تساهم شركات رأس المال المخاطر في تمويل المؤسسات الصغيرة والمتوسطة بالولايات

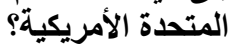
و سعيا للإجابة على هذه الإشكالية قمنا بتفكيكها إلى سؤ الين فر عيين على النحو التالي:

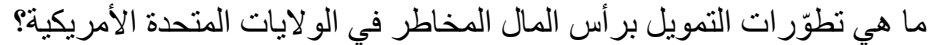

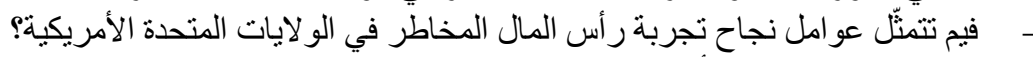
وفي ضوء إنثكالية البحث وكذا الأسئلة الفرعية المطروحة نتطلق في دراستتا من عدة فرضيات أساسية

- تقدّم شركات رأس المال المخاطر مساهمات تمويلية كبيرة للمؤسسات الصغيرة والمتوسطة

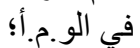

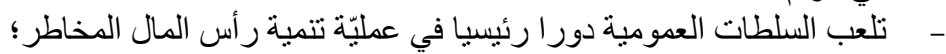

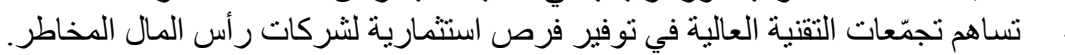

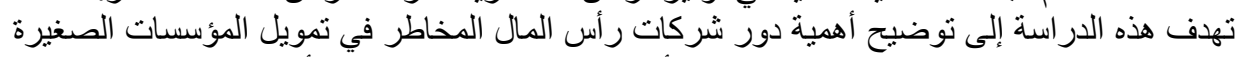

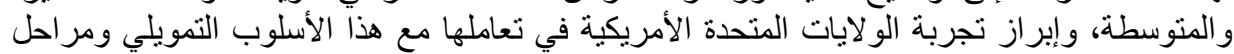

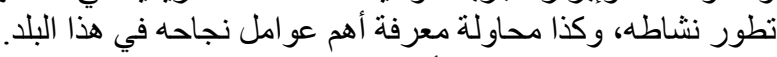
I - I الإطار المفاهيمي لرأس المال المخاطر:

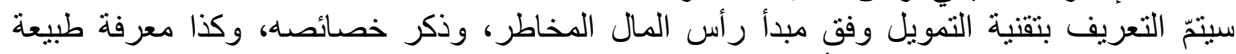

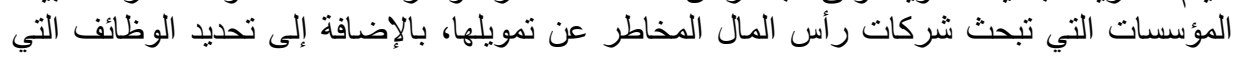


تضطلع بها الثركات التي تعمل وفق هذا الأسلوب التمويلي، وفي الأخير توضيح ايجابيات وسلبيات

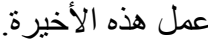

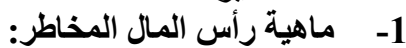

عرّفته الجمعية الوطنية الأمريكية لرأس المال المخاطر (NVCA) بأنّه: "الأموال التي يمنحها أشخاص

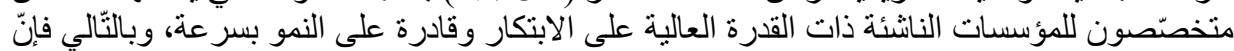

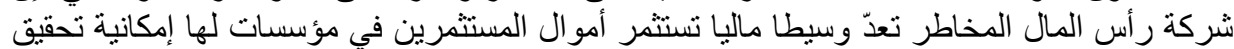

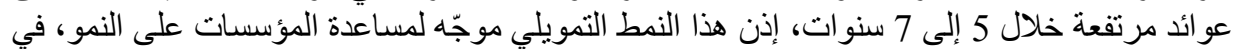

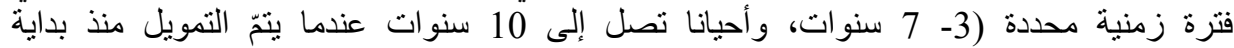

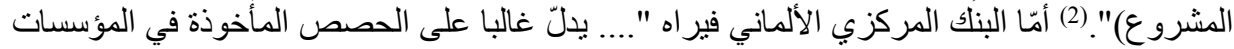

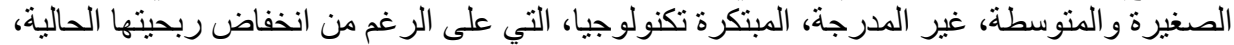

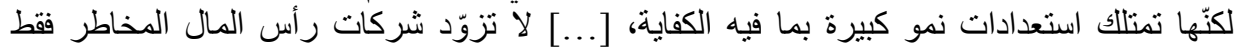

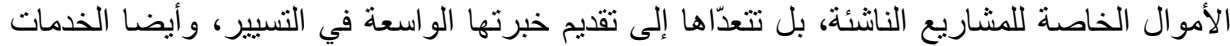

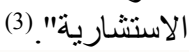

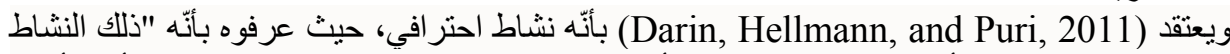

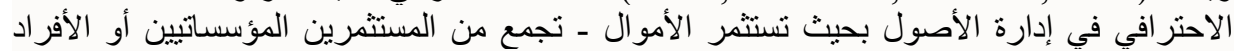

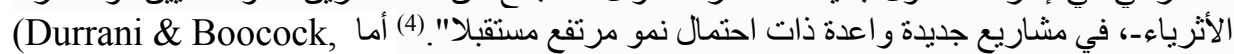

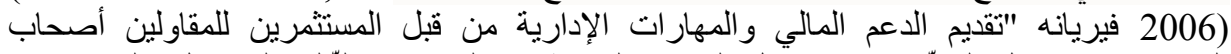

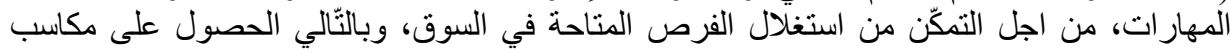

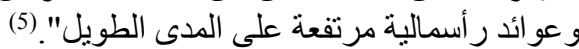
من خلال استعر اض التعاريف السابقة، نجد أنّها تتقاطع فيما بينها إلى حد كبير ، ويعكس الاختلاف بينها

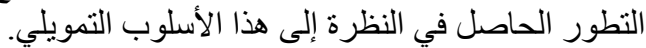

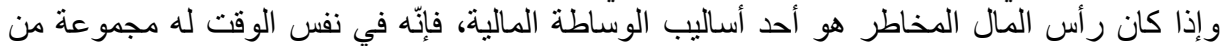

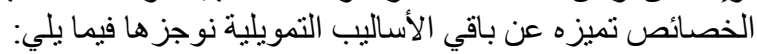

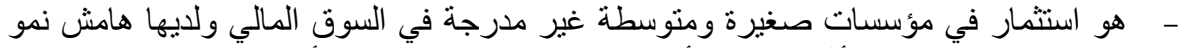

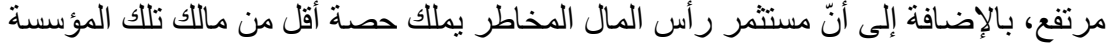
؛(un apport minoritaire) مدّة هذا الاستثمار تكون في الغالب محدودة بنجاح نمو المؤسسة (3-7 سنوات)، لكن تاريخ

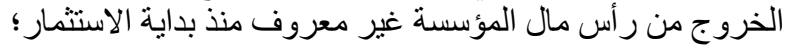

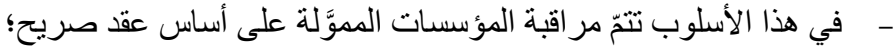

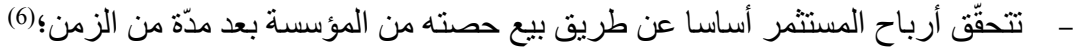

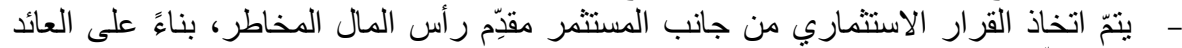

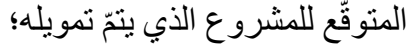

غالبا ما تتميّز المؤسسات المموَّلة بر أس المال المخاطر بارتفاع المخاطر ، وعو ائدها المتوقعة كبيرة؛

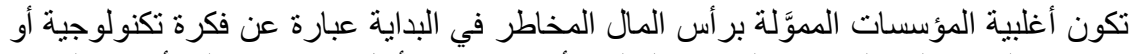

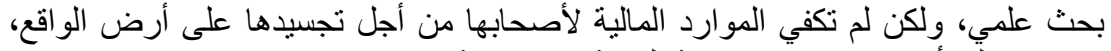

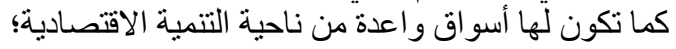

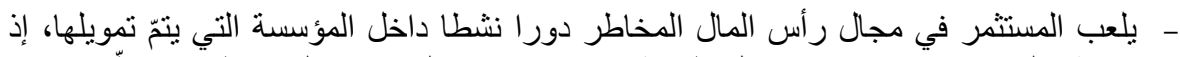

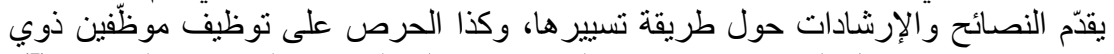

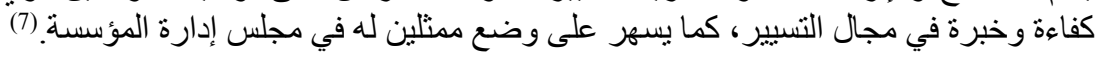


2-2 طبيعة المؤسسات المموَّلة عن طريق شركات رأس المال المخاطر :

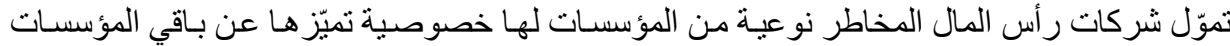

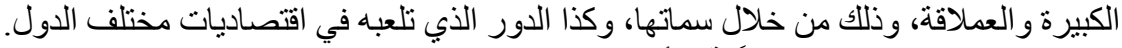

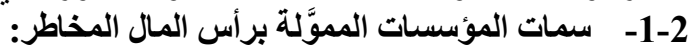

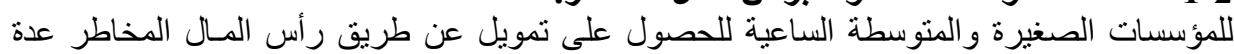
سمات، يمكن إيجاز ها في النقاط التالية:

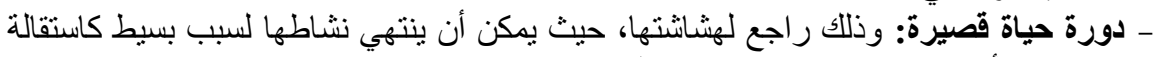

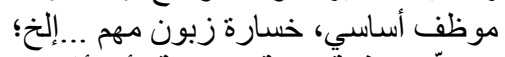

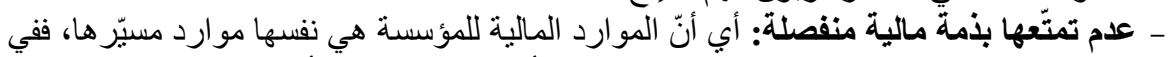

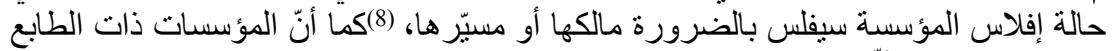

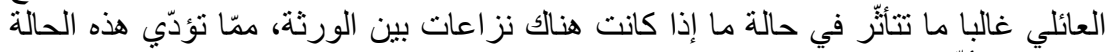

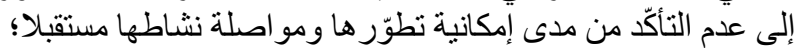

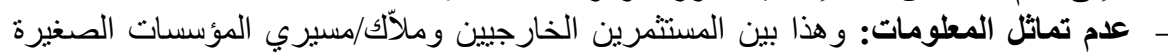

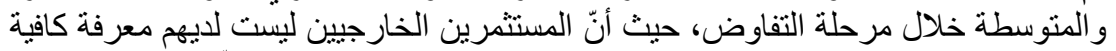

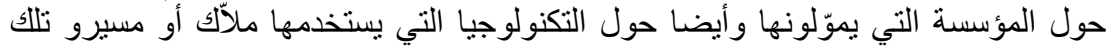

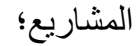
- ضعف قدرة التمويل الأتي: حيث تتميّز بعدم كفاية قدرتها على التمويل الذاتي، وكذا ضعف

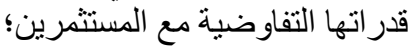
- عدم القيد في السوق المالي: فهي غير مدرجة في المئئ السوق المالي وبالتالي عجز المعلومات

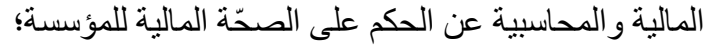

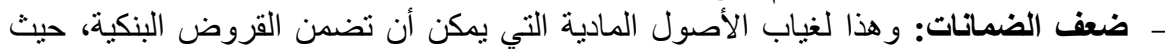

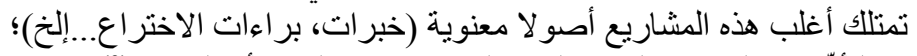

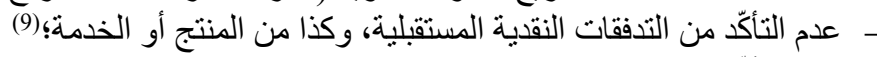
- - عدم التأكّد من الكفاءات التسييرية الفعلية.

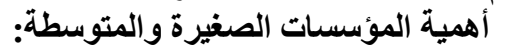

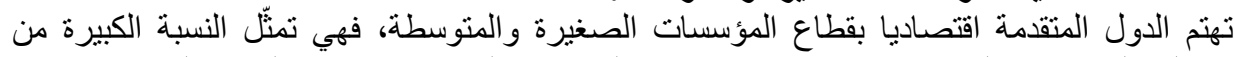

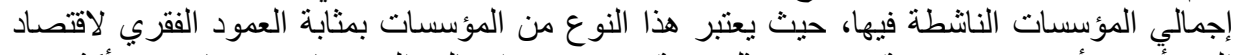

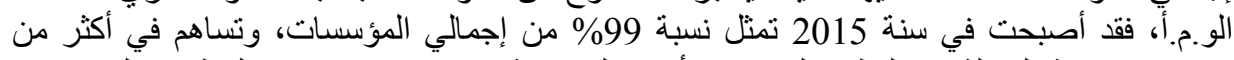

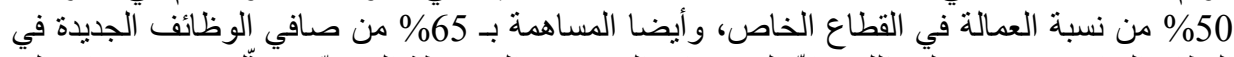

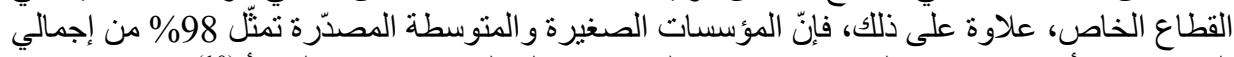

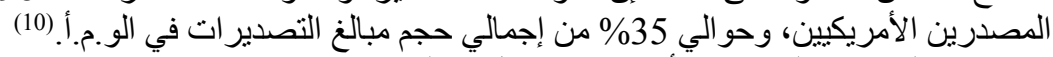

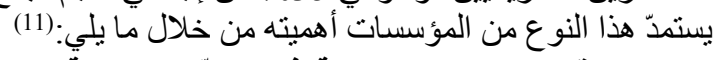

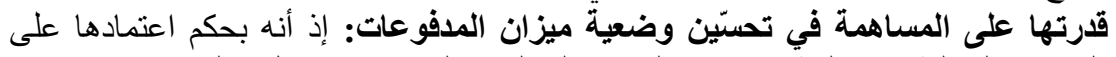

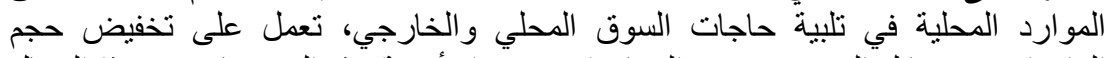

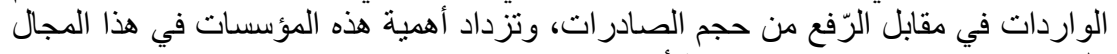
كلما ازدادت جودة منتجاتها وتنافسية أسعار ها؛

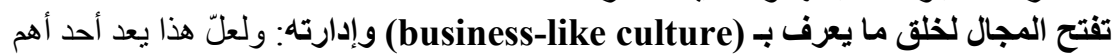

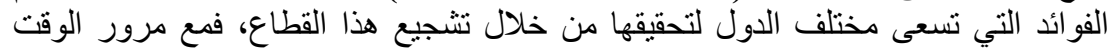

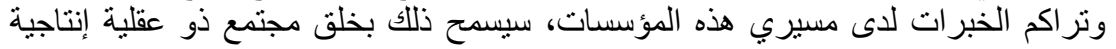
قادر على تتمية الاقتصاد مستقبلا، وخير دليل لئلى على ذللك تجربة كل من اليابان و العديد من

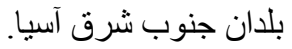
3- وظائف شركات رأس المال المخاطر: 
ترتبط وظائف شركة رأس المال المخاطر بعملية متتابعة بين الاستثمار ومتابعة المشاريع، حيث بمكن تقسيمها إلى ستة وظائف رئيسية:

تجميع الموارد المالية من المستثمرين: لا يطرح تجميع الأمو ال بالنسبة لشركات رأس المال

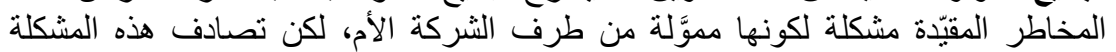

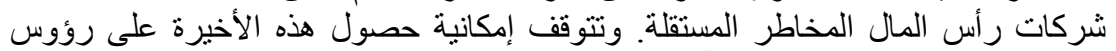

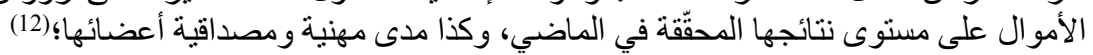

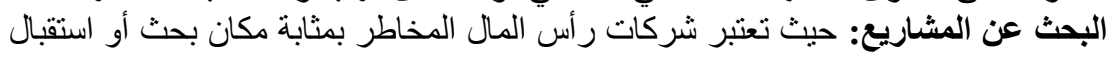

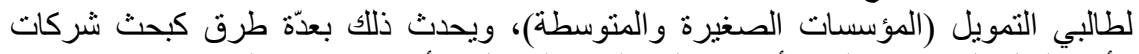
رأس المال المخاطر عليها، أو استقبال طلبات التمويل، أو بالاعتماد على وسطاء يقاء يقترحون

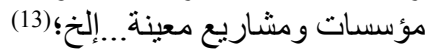

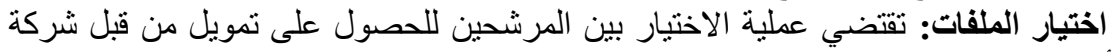

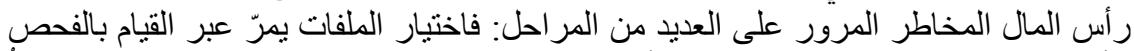

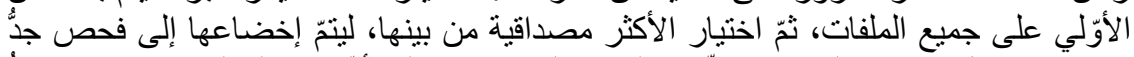

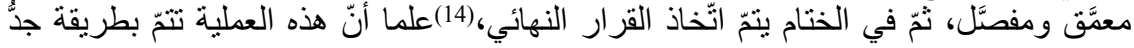

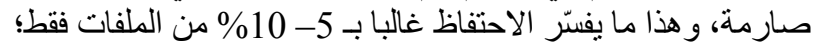

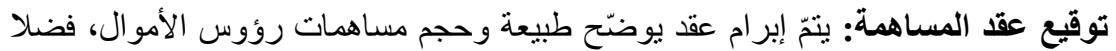
عن تحديد الإستر اتيجيات وطبيعة العلاقة ما بين المؤسسة وشركة رأس المال المخاطر النّاتجة

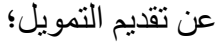

التذخل في نشاط المؤسسة ومتابعته: هناك العديد من أشكال المساعدات التي تستفيد منها

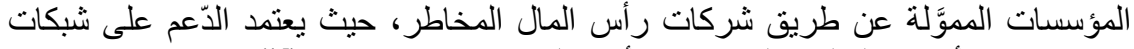

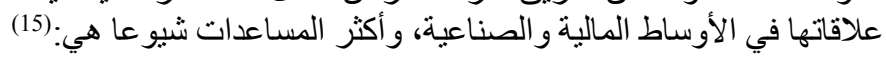

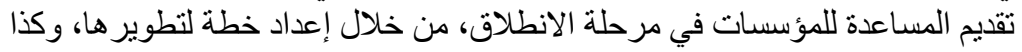
إعداد نظام لمر اقبة التكاليف، إضافة إلى كل الخدمات التي تسمح بنحويل المشروع التهان

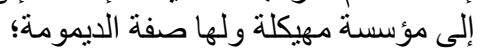

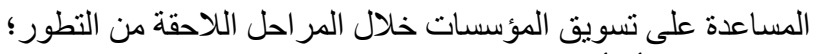

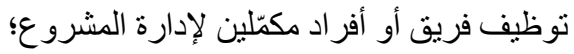

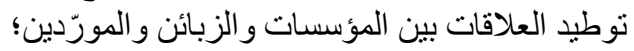

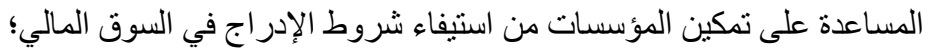

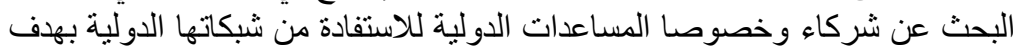

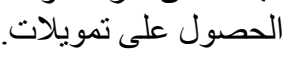

عمليات الخروج: في النهاية، أب بعد مضي 5 - 10 سنولئ سنوات من المساهمة (في المتوسط)،

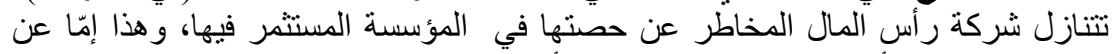

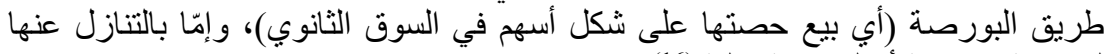
لمؤسسة صناعية أو لمؤسسة مالية. 
الثكل رقم (1): دورة نشاط شركات رأس المال المخاطر

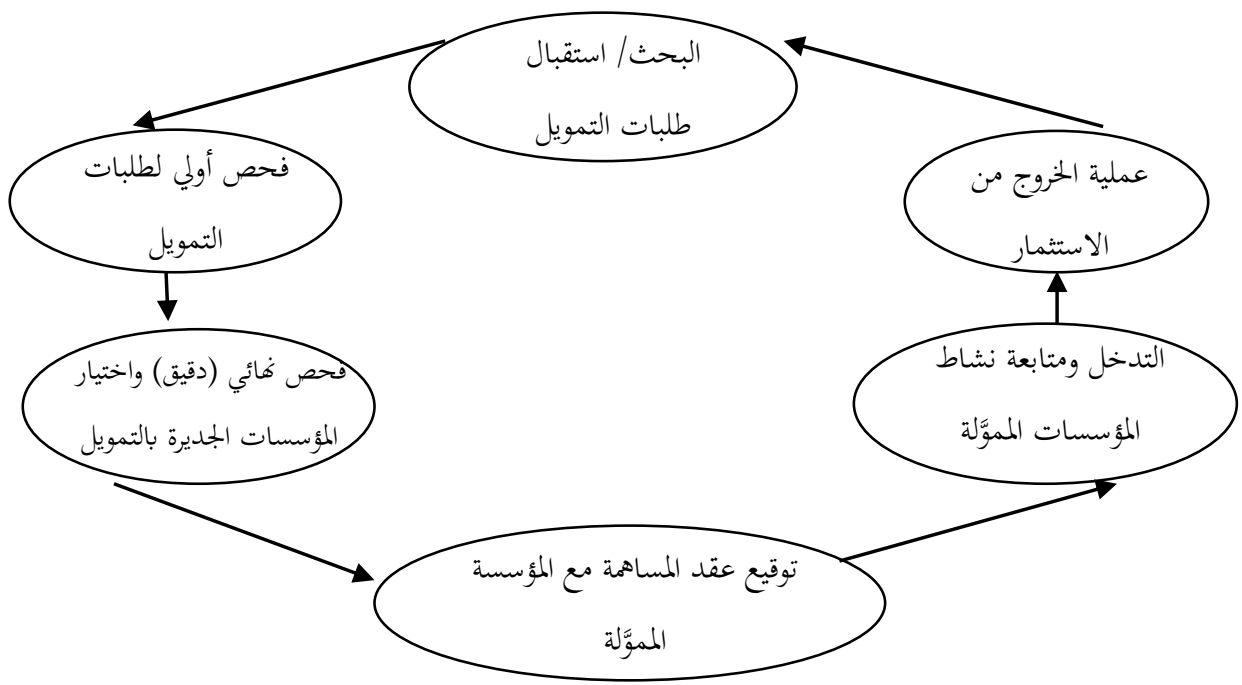

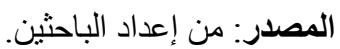

-4 - ايجابيات وسلبيات شركات رأس المال المخاطر:

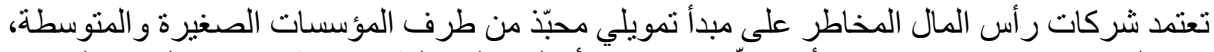

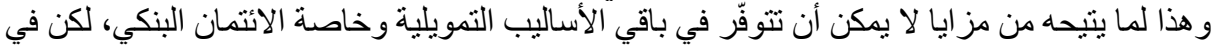

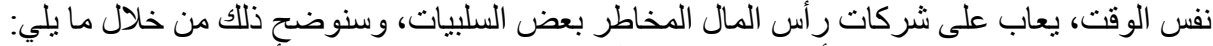

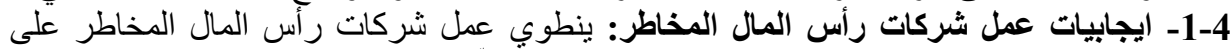
العديد من الايجابيات التي تميز ها عن باقي مصادر التمويل، تثنتّل أهمّها فيما يلي:

المرحلية: لا يكون التمويل برأس المال المخاطر دفعة واحدة بل يكون مرحلة بمرحلة، فكلّما

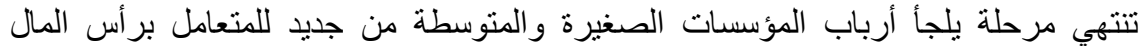

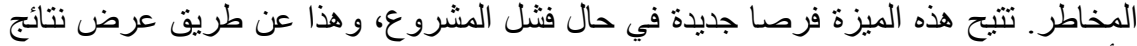

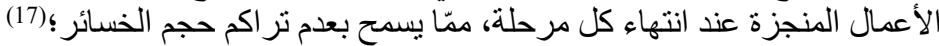

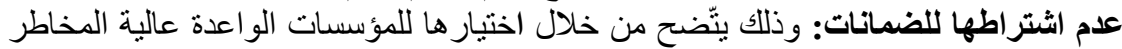

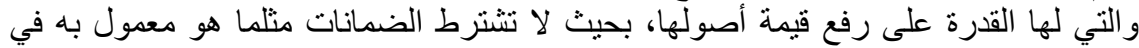
البنوك؛

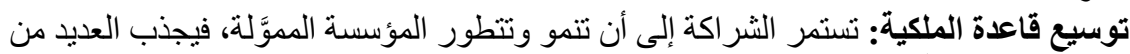

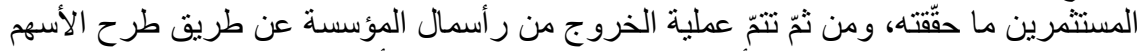

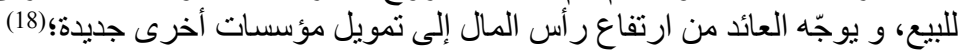

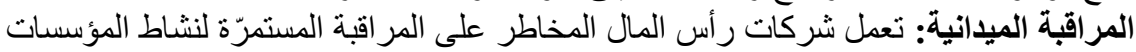

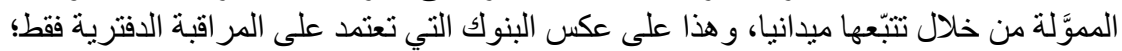

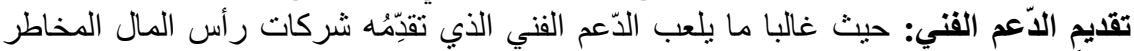
دورًا هامًا في نجاح المؤسسات المموَّلة، إضافة إلى توفيرها للمساهمة طويلة الأجل (أقل أو أو 
تساوي 10سنوات)، و هذا يرجع لمبدأ هذا التمويل في عدم الخروج من رأسمال المؤسسة إلاّ في

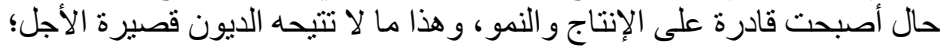

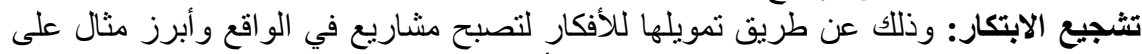

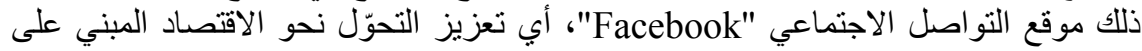

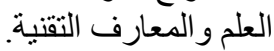

2-4- سلبيات عمل شركات رأس المال المخاطر: بمكن لثركات رأس المال المخاطر أن تصبح عبئًا

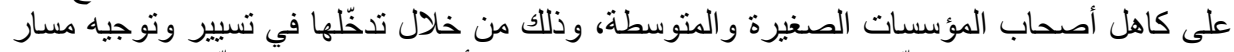

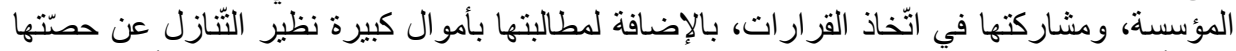

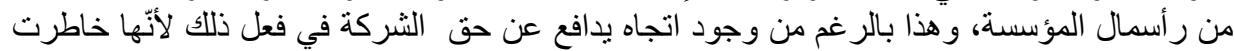

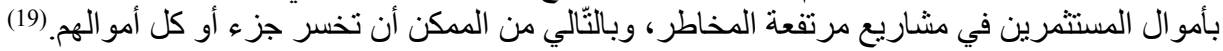

تجربة الولايات المتحدة الأمريكية في التمويل عن طريق شركات رأس المال المخاطر:

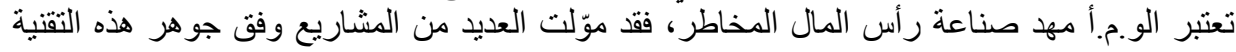

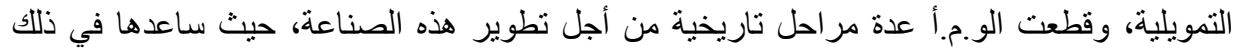

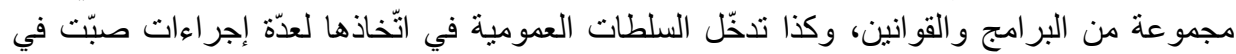

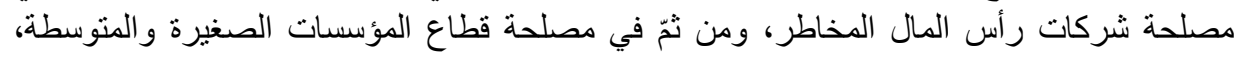
بالإضافة إلى عو امل أخرى ساعدت على الهال الهذاح الو.م.أ في العمل وفق هذه التقنية التمويلية.

1- مراحل تطور صناعة رأس المال المخاطر في الولايات المتحدة الأمريكية:

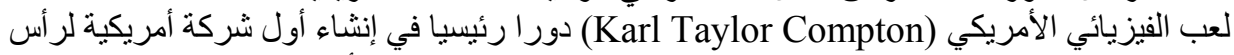

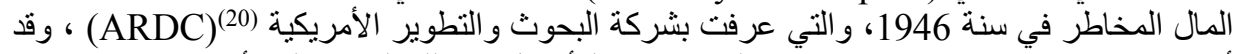

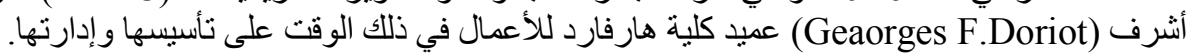

حصلت شركة البحوث والتطوير الأمريكية على تمويل مبدئي من طرف شركات التأمين، وفي سنة

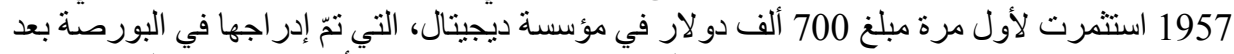

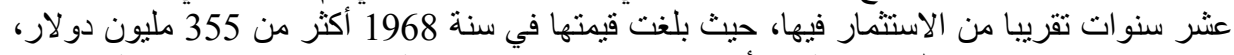

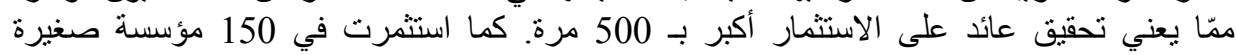

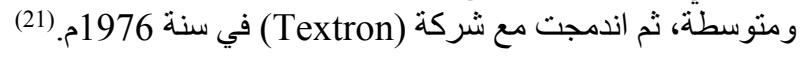

شهدت صناعة رأس المال المخاطر الأميركية منذ نشأتها في سنة 1946 مجموعة من المراحل التاريخية، سنحاول حصر ها ما بين فترة الانطلاقة الحقيقية في الثمانينيات إلى غاية سنة 2015، وتم تقسيم هذه المر احل وفقا لما يلي:

1-1-1 مرحلة الانطلاقة الحقيقية لراس المال المخاطر (1980- 1991): شهخ مسار صناعة رأس المال المخاطر الأمريكية طفرة منذ بداية الثمانينات من القرن العشرين، ويرجع ذذلك إلى عاملين رئيسيين هما:

تخفيض نسبة الضر ائب على الأرباح الر أسمالية في سنة 1978، ثم أيضا في سنة 1981، ممّا

حفّز على إنشاء شركات وصناديق رأس المال المخاطر جديدة؛ (22) 
قانون تأمين دخل تقاعد الموظف: ويرجع ذلك إلى سنة 1979، حين سمح هذا القانون

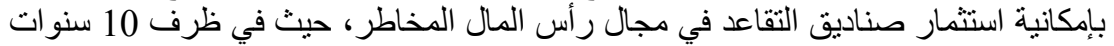

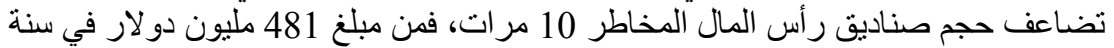

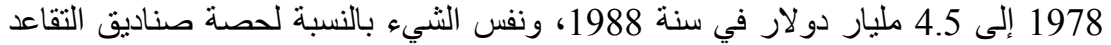
حيث انتقلت من 17\% في سنة 1980 إلى 50\% في بداية التنسعينيات. (23)

الثكل رقم (2): استثمارات رأس المال المخاطر في الو.م.أ خلال الفترة 1980- 1991

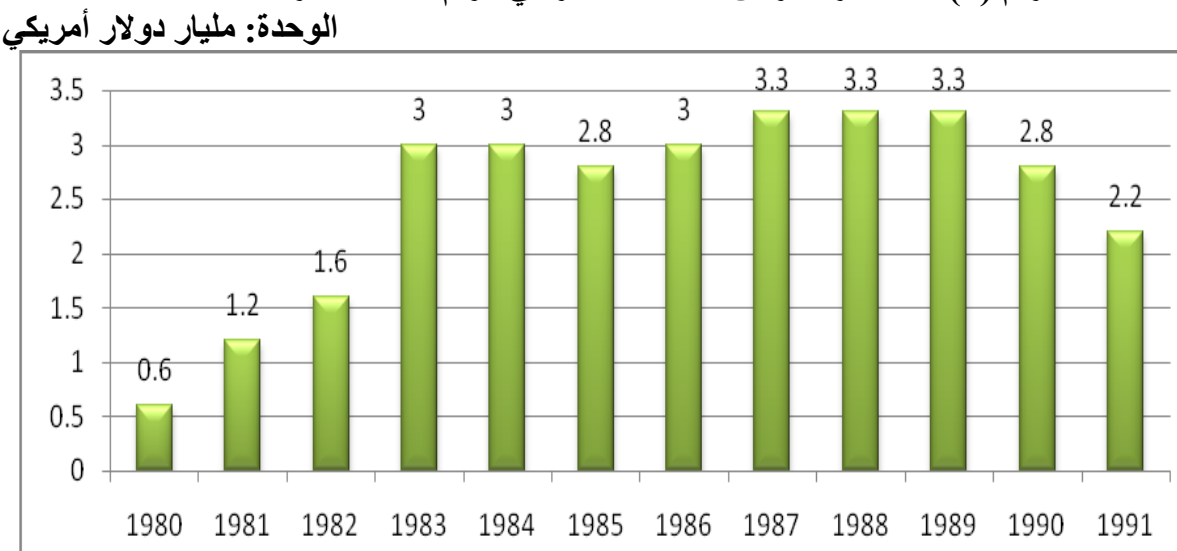

Source : Jarunee Wonglimpiyarat, The dynamic economic engine at Silicon Valley and US Government programmes in financing innovations,

Technovation, n26, 2006, p1086.

من الثكل رقم (2)، يتّضح أن مستوى الاستثمارات لم يتجاوز عنبة 600 مليون دو لار في سنة 1981 1980،

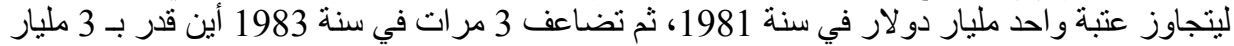

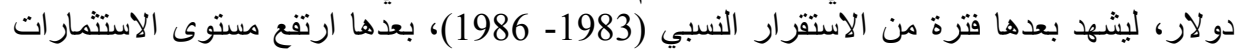

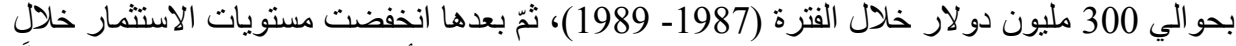

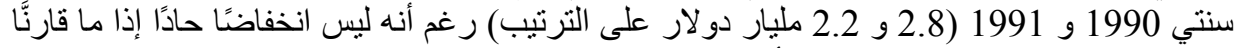

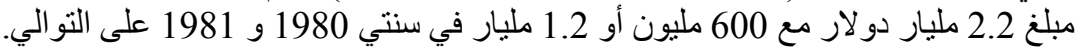

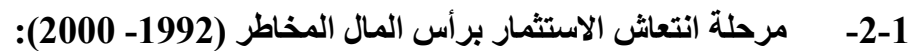

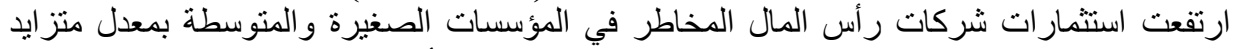

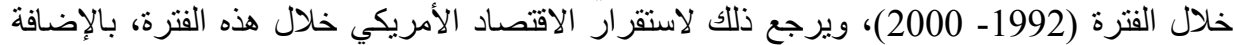

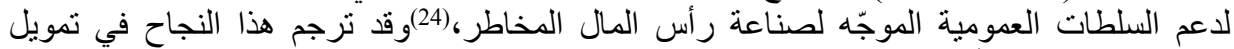

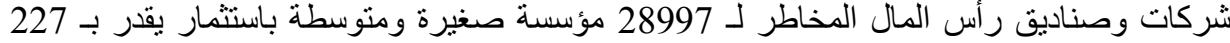
مليار دو لار من سنة 1992 إلى غاية سنة 2000. 
الثكل رقم (3): استثمارات رأس المال المخاطر في الو.م.أ خلال الفترة 1992- 2000 الوحدة: مليار دولار أمريكي المي المان

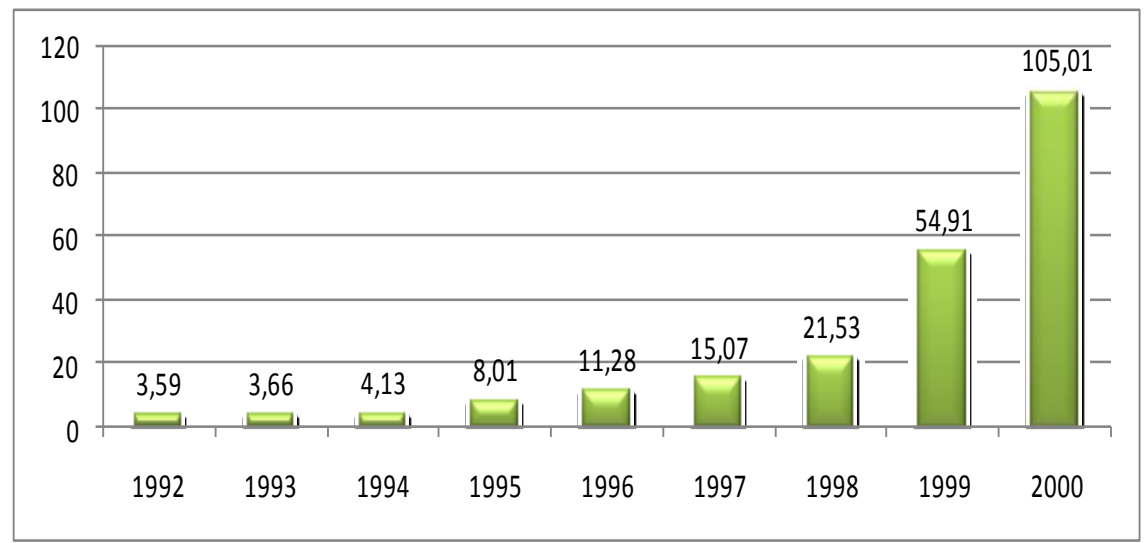

المصدر: تم إعداد الثكل بالاعتماد على معطيات الجمعية الأمريكية لرأس المال المخاطر من خلال

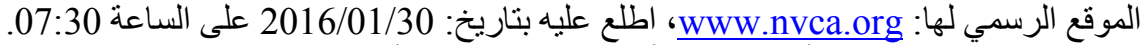

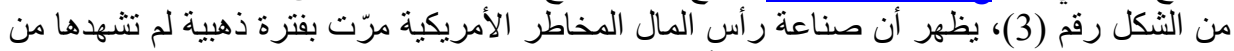

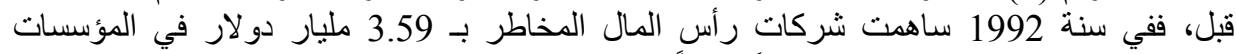

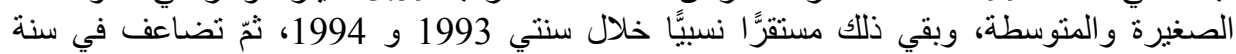

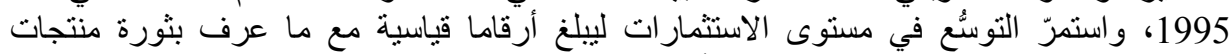

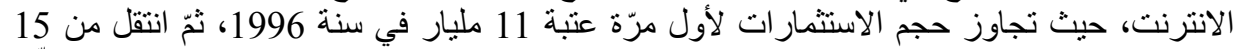

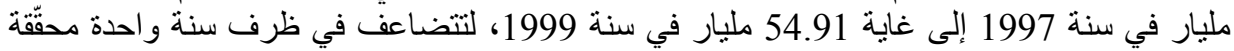

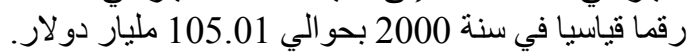
ويرجع سبب هذا التزايد المستمر في الاستثمارات لارتفاع القار القيمة السوقية لأسهم مؤسسات الأعمال

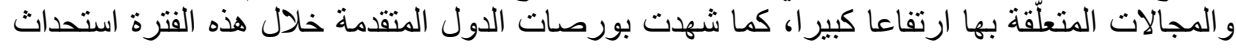

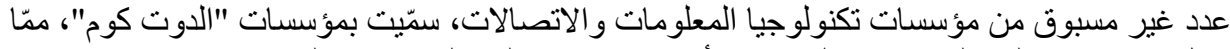

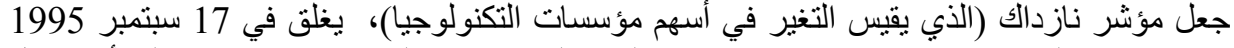

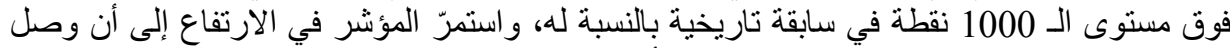

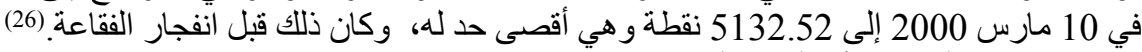

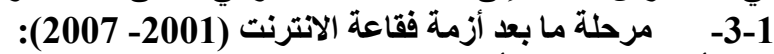

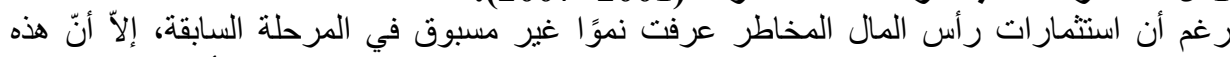

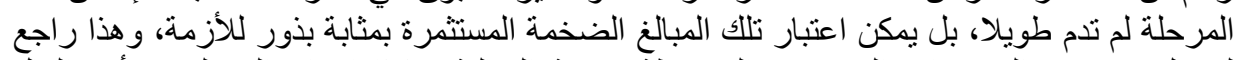

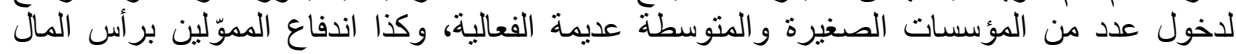

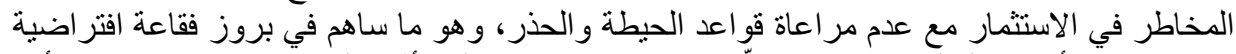

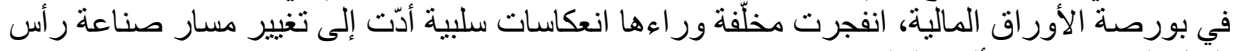

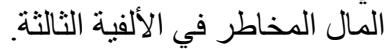


ولقد انجر عن انفجار فقاعة الانترنت عدة انعكاسات سلبية لعلّ أبرزها انخفاض مسنويات مؤشر فئر

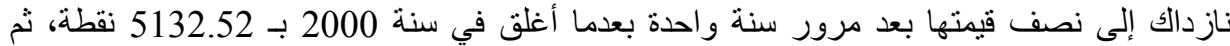

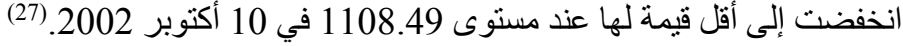

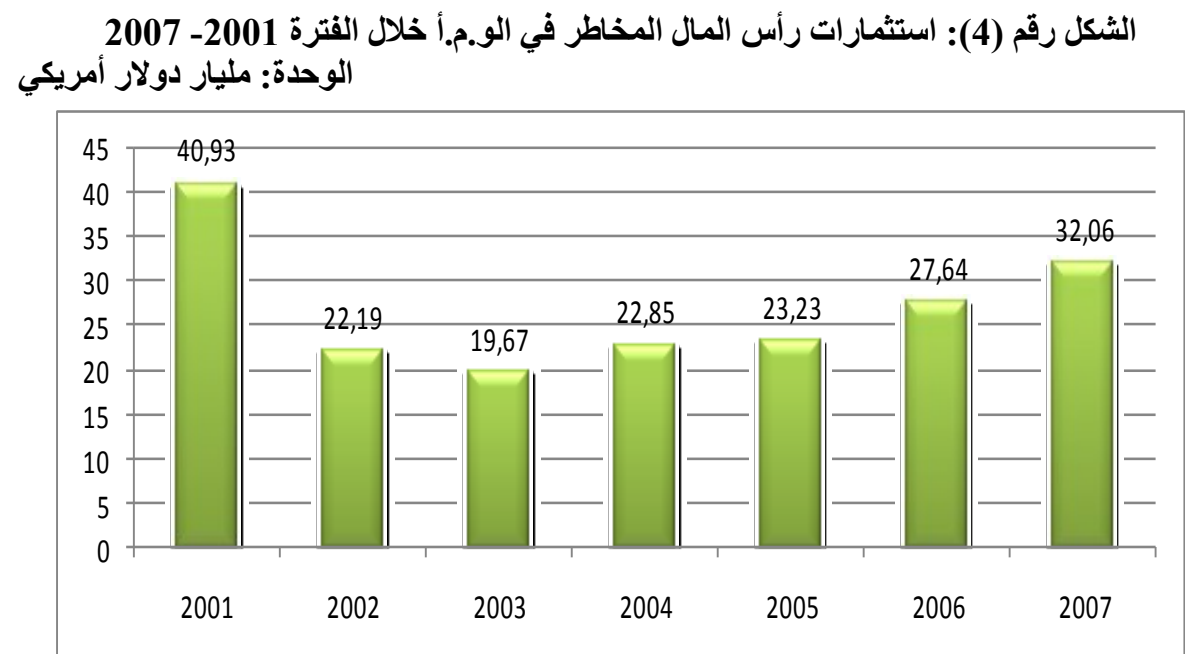

المصدر: تم إعداد الثكل بالاعتماد على معطيات الجمعية الأمريكية لر أس المال المخاطر من خلال

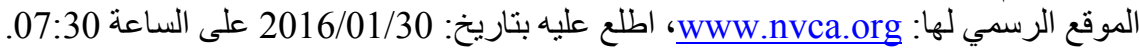

بنّضّح من خلال الثنكل رقم (4)، أنّه حدث سقوط حر في مستوى الاستثمارات بفعل انفجار فقاعة

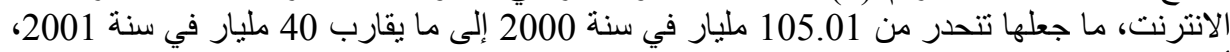

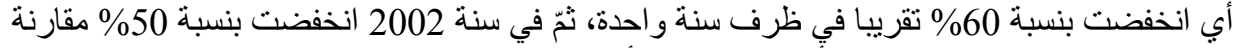

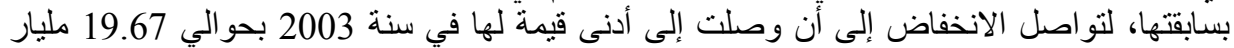

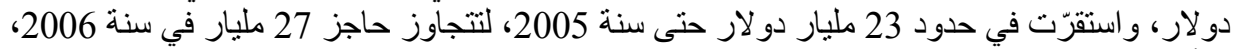

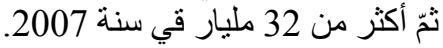

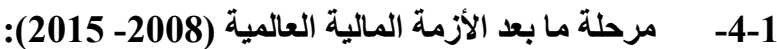

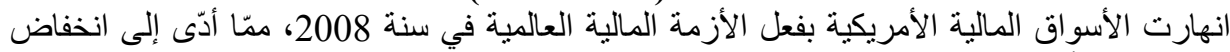

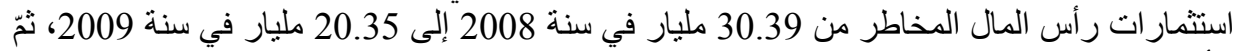

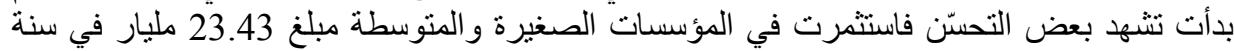

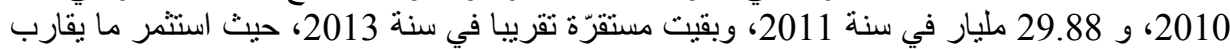
30.06 مليار في نفس السنة.

وبعدما بدأ الاقتصاد الأمريكي يتعافى من الأزمة المالية، بدأت صناعة رأس المال المخاطر الأمريكية

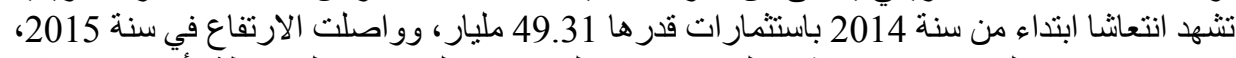

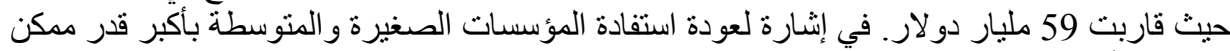
من هذا الأسلوب التمويلي. (انظر الثكل5)

الثكل رقم (5): استثمارات رأس المال المخاطر في الو.م.أ خلال الفترة 2008- 2015 
مساهمة شركات رأس المال المخاطر في تمويل المؤسسات الصغيرة والمتوسطة حالة الولايات المتحدة الأمريكية في الفترة (1980-2015)

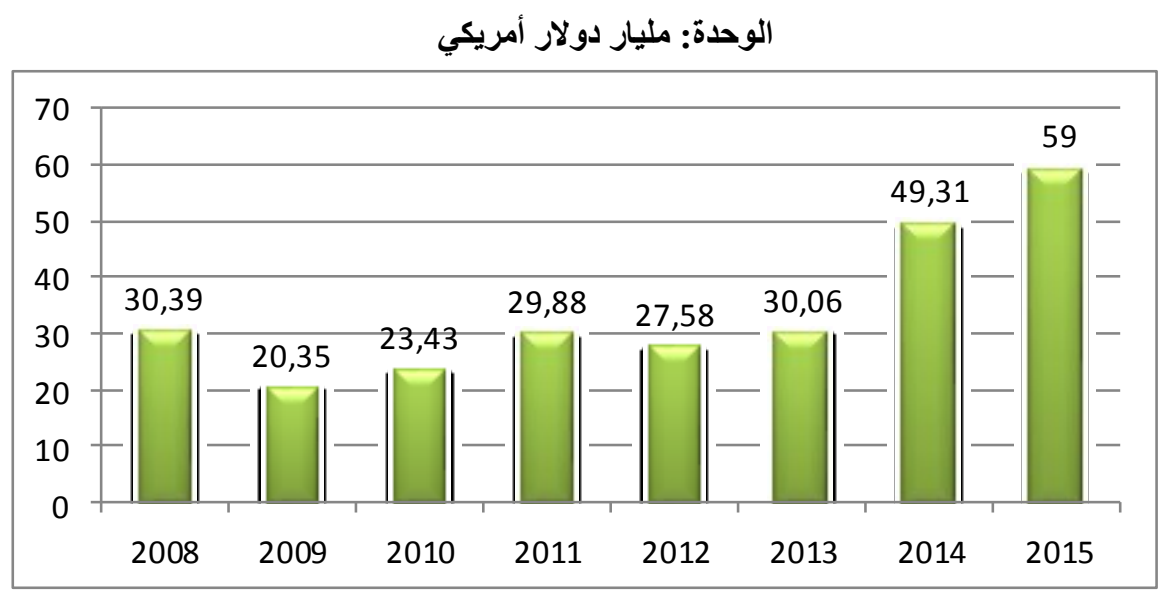

المصدر: تم إعداد الثكل بالاعتماد على معطبات الجمعية الأمريكية لر أس المال المخاطر من خلال

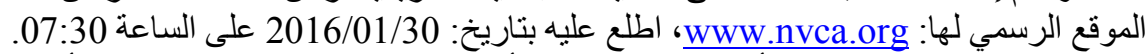

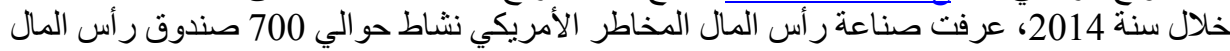

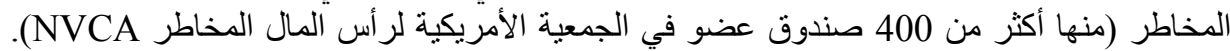

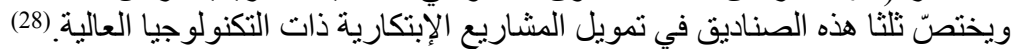
الثكل رقم (6): استثمارات رأس المال المخاطر في الو.م.أ حسب قطاعات الكبات النشاط خلال سنة 2014

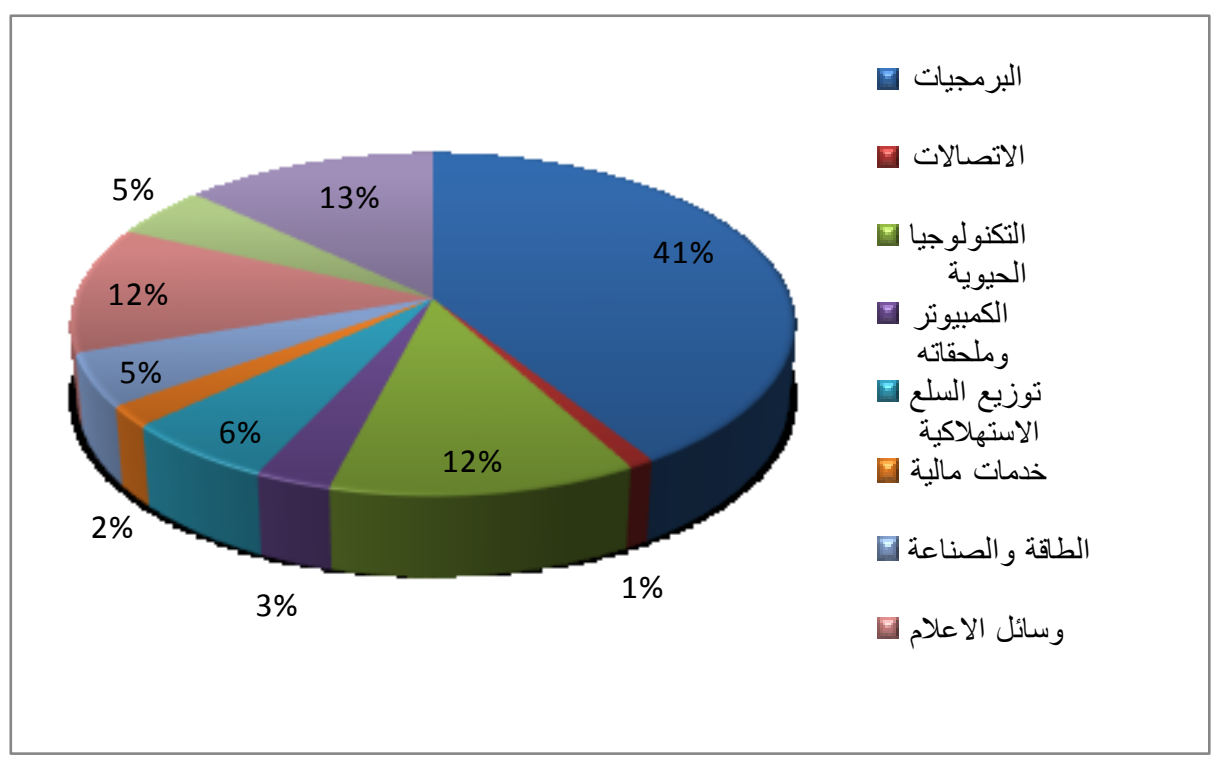

المصدر: تم إعداد الثكل بالاعتماد على معطيات الجمعية الأمريكية لرأس المال المخاطر من خلال

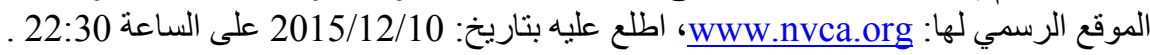


ثركّزت النسبة الكبرى من تمويلات المتعاملين برأس المال المخاطر في قطاعات التكنولوجيا،

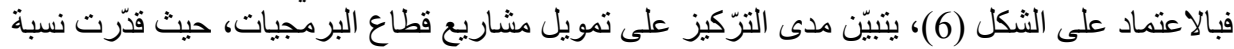

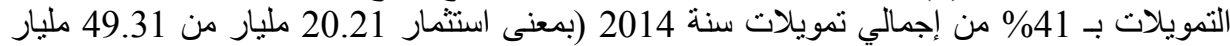

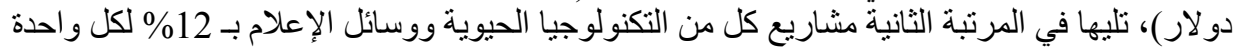

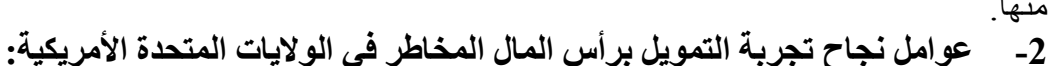

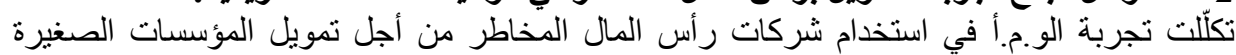

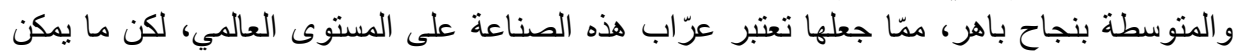

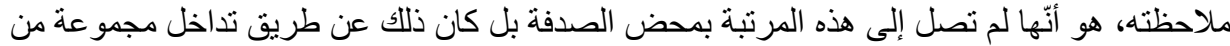

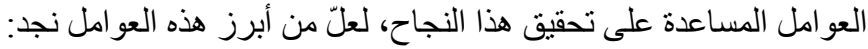

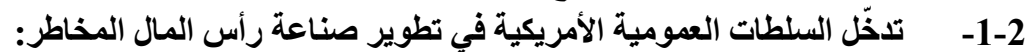

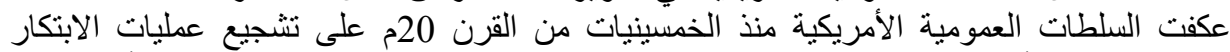

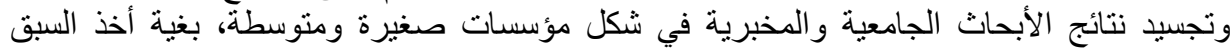

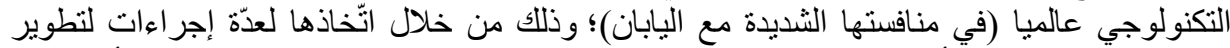

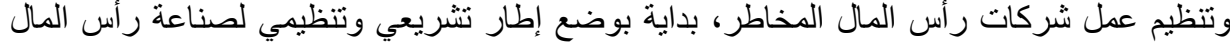

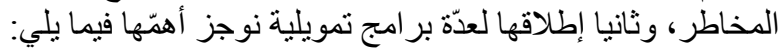

- برنامج شركات الاستثمار في المؤسسات الصغيرة (Company)

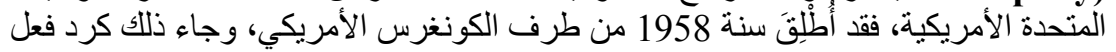

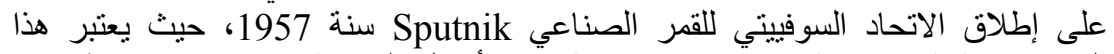

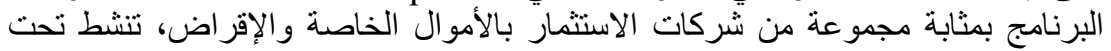

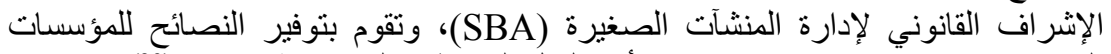

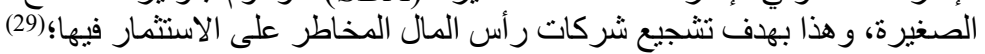

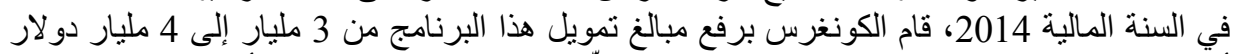

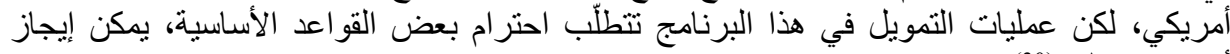

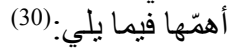

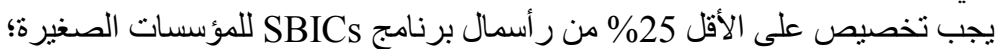

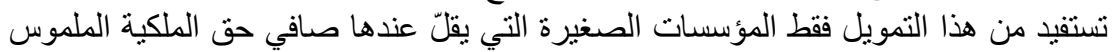
(tangible net worth) الدخل للسنتين الماليتين السابقتين أكثر من 6.5 مليون دو لار.

- برنامج بحوث الابتكار الخاص بالمؤسسات الصغيرة (Small Business Innovation) Research)

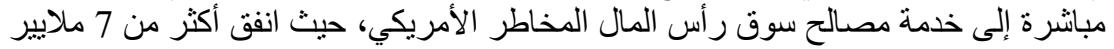

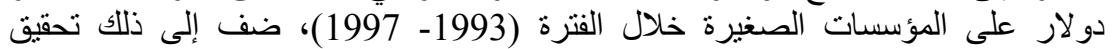

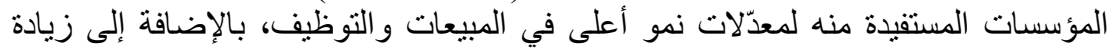

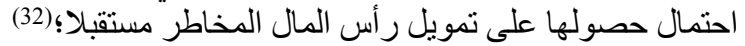

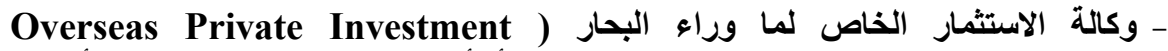
(Corporation

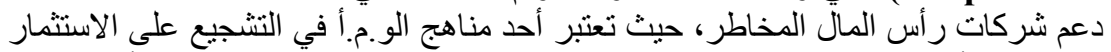

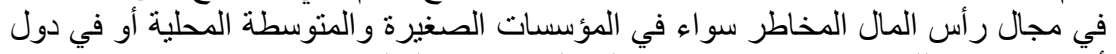
أخرى، فهي تملك استثمار ات في 160 دولة في لملى مستوى العالم؛ (33) 
- برنامج نقل تكنولوجيا المؤسسات الصغيرة 1The Small Business Technology Transfer) التي تتوصل إليها الجامعات و المخابر الحكومية.

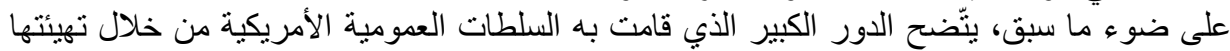

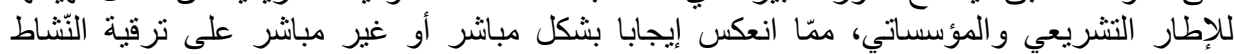
التمويلي لر أس التمال المخاطر. 2-2-2 - تطور السوق التكنولوجي وديناميكيته:

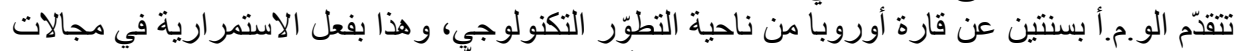

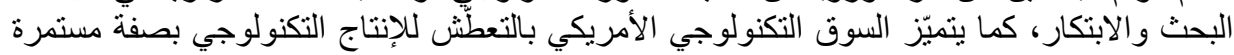

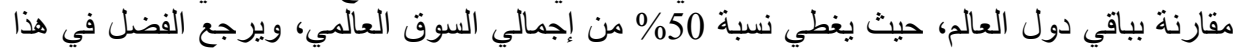

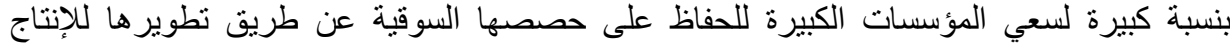
التكنولوجي لاى المؤسسات الصغيرة ولئ والمتوسطة.

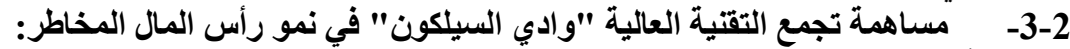

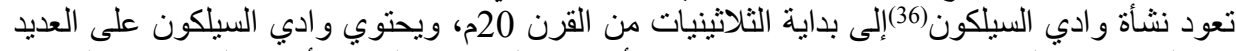

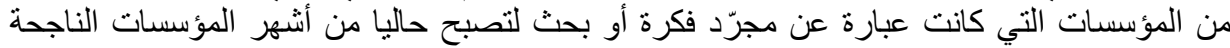

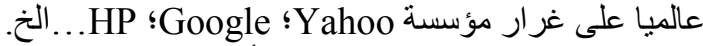
الثكل رقم (7): إجمالي تمويلات رأس المال المخاطر للمؤسسات في وادي السيلكون خلال الفترة

(2001 -1990)

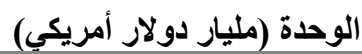

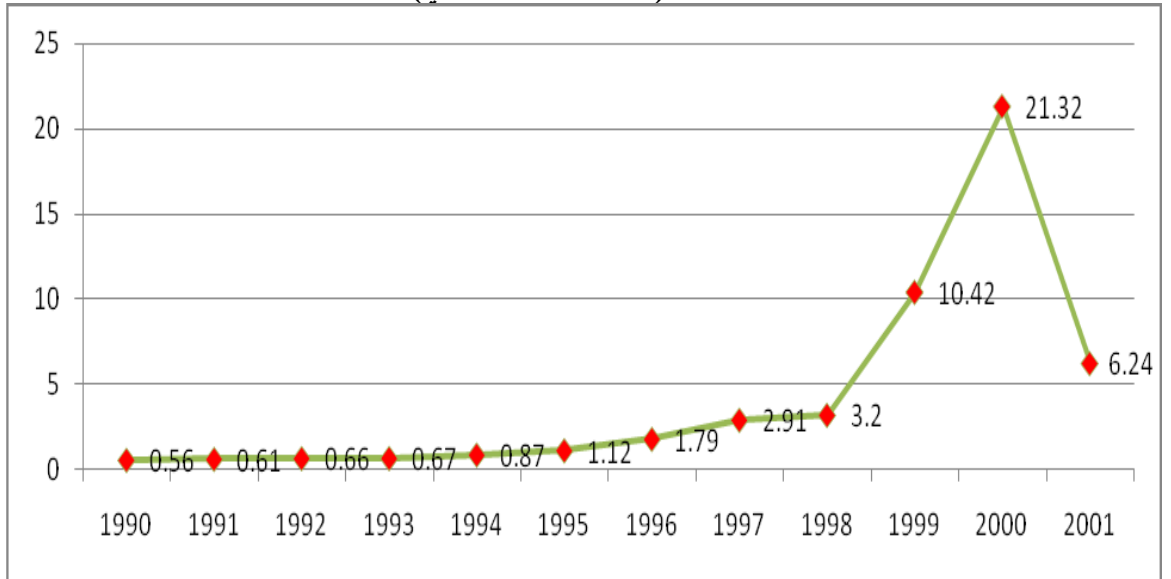

Source : Jarunee Wonglimpiyarat, The dynamic economic engine at Silicon Valley and US Government programmes in financing innovations, Op cit, P1087.

بعتبر وادي السيلكون ركيزة أساسية في تطوّر ونجاح نشاط رأس المال المخاطر الأمريكي، ففي سنة

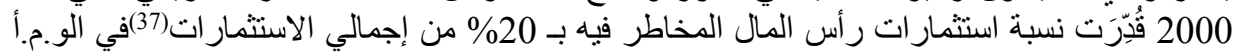

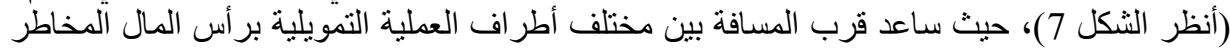
(المؤسسات الصغيرة و المتوسطة، شركات رأس المال المخاطر ...) على نجاحه. 


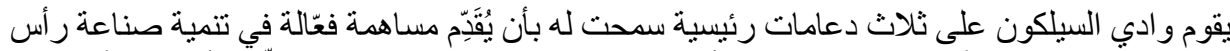

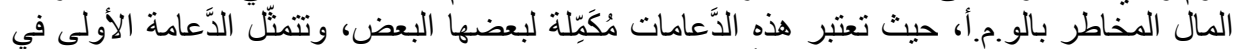

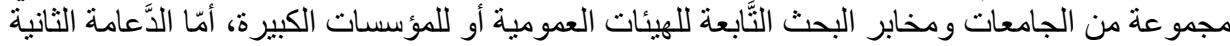

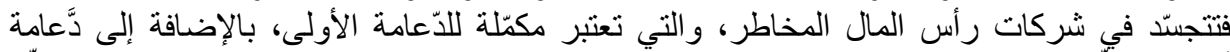

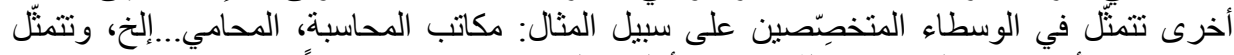

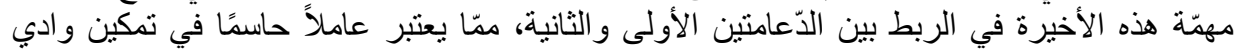

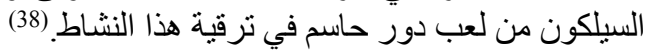

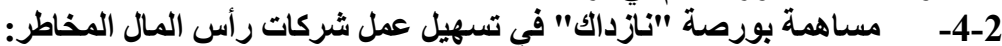

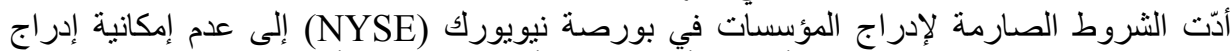

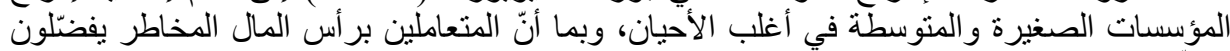

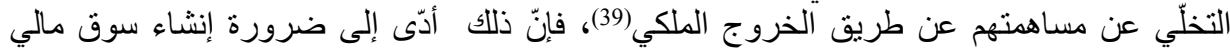

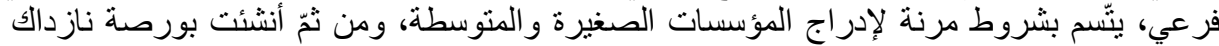
NASDAQ

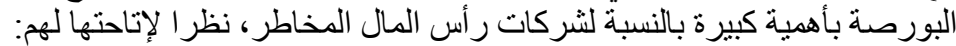

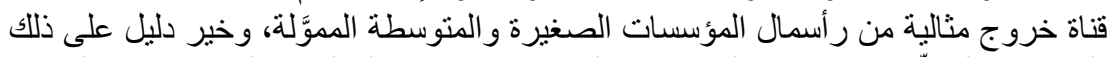

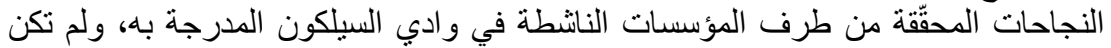

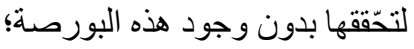

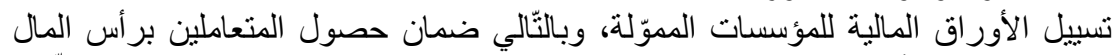

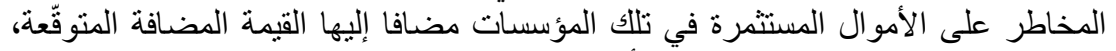

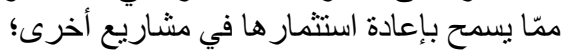
إنعاش التمويل عن طريق رأس المال المخاطر ، وبالتّالي تتمية وتطوير المؤسسات، ومن ثمّ إنعاش النشاط الاقتصادي.

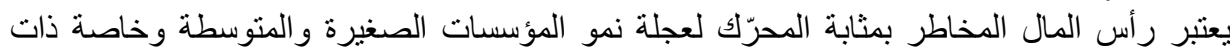

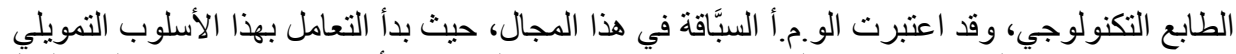

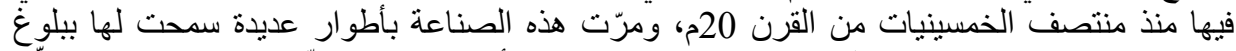

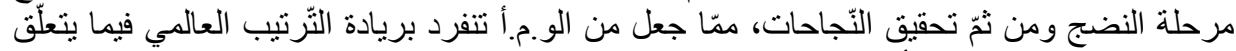

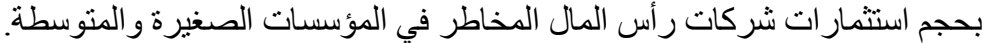

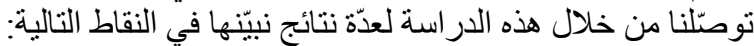

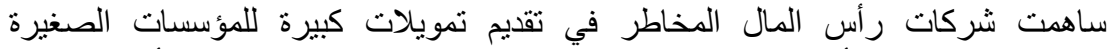

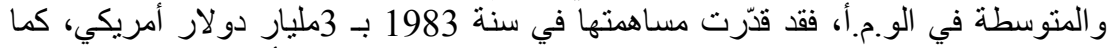

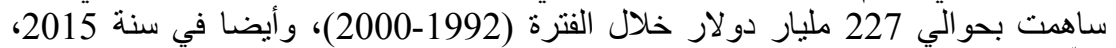

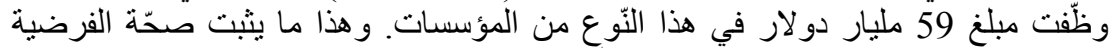

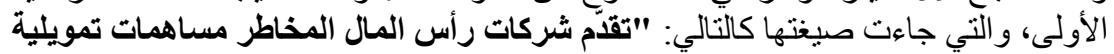

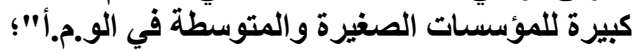

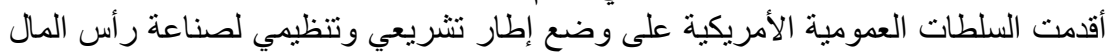

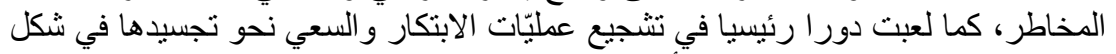

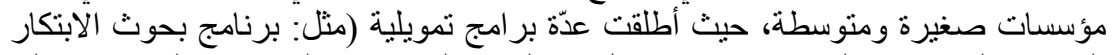

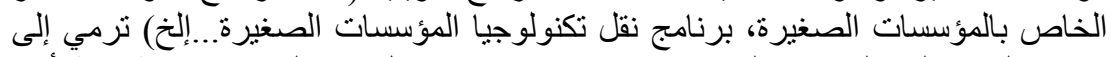

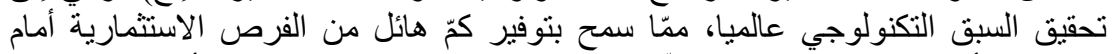

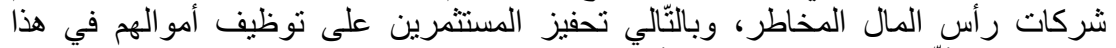

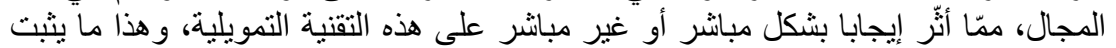


صحّة الفرضية الثانية، والتي جاءت صيغتها كالتالي: "تلعب السلطات العمومية دورا رئيسيا

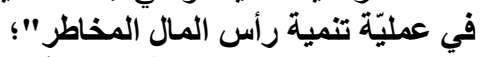

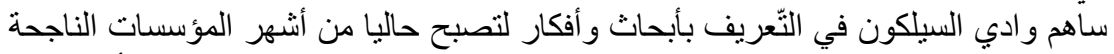

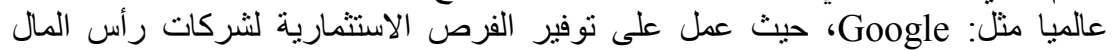

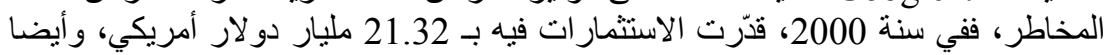

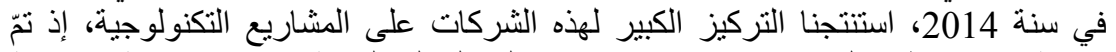

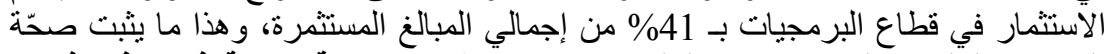

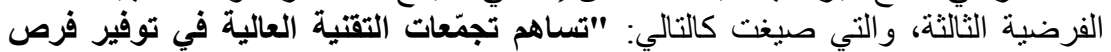

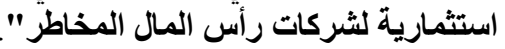

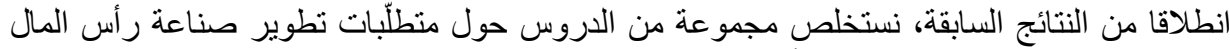

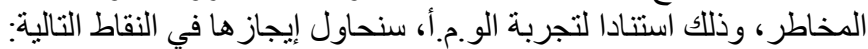

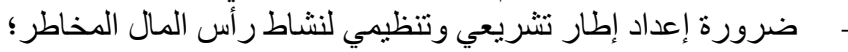

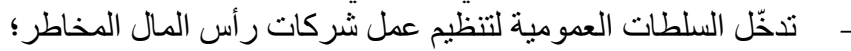

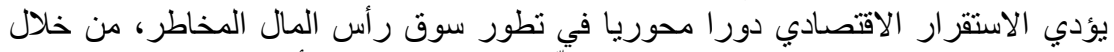

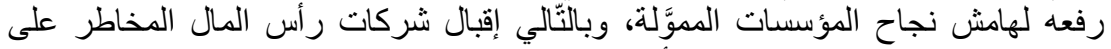

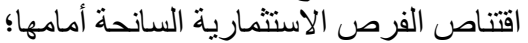

تخفيض نسبة الضرائب على الأرباح الرأسمالية، ممّا سيحفّز المستثمرين على نوظيف

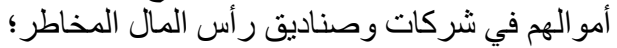

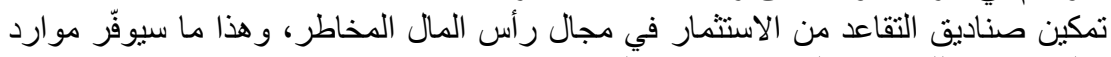

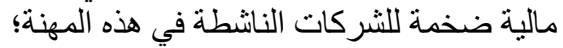

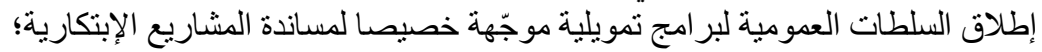

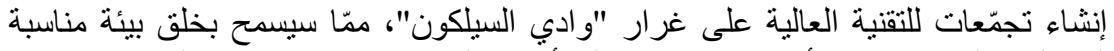

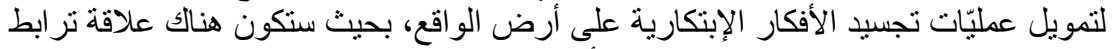

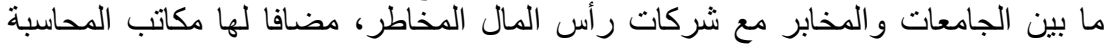

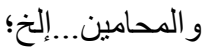

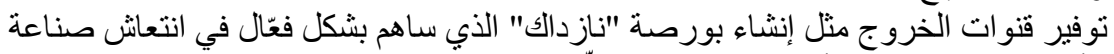

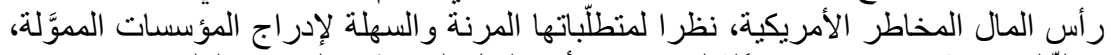

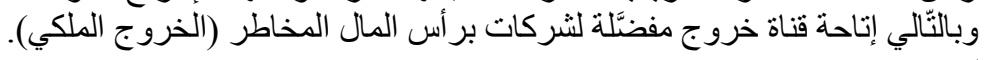

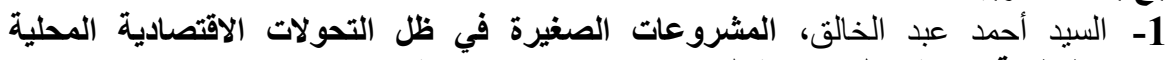

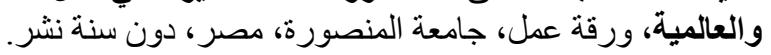

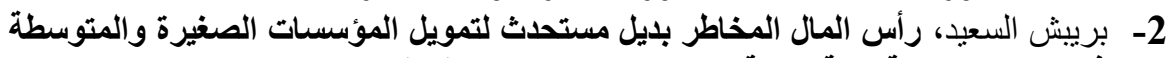

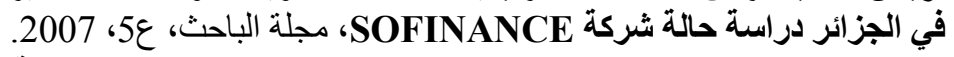

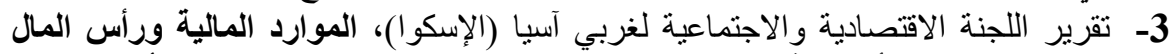

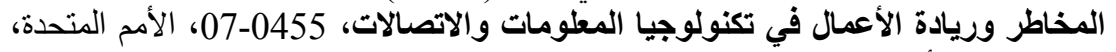

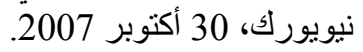

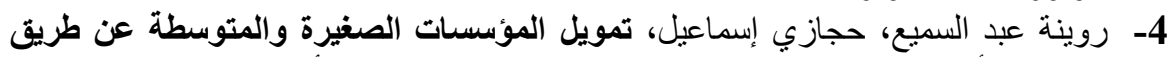
شركات رأس المال المخاطر، الملتقى الدولي حول: منطلبات تأهيل المؤسسات الصغيرة 


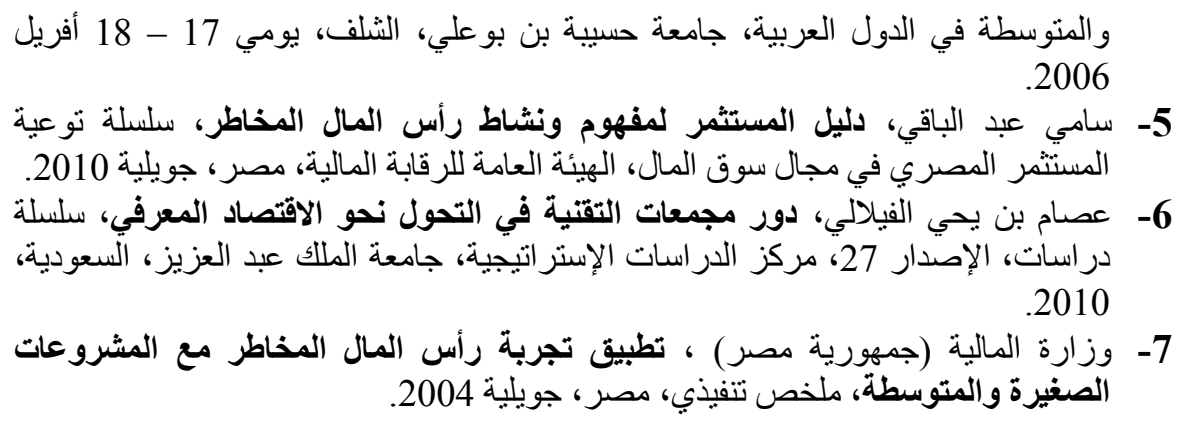

1- Alexander Haislip, Essentials of Venture Capital, Published by John Wiley \& Sons, Inc, New Jersey, U.S.A, 2011.

2- Arnd Plagge, Public Policy for Venture Capital -A Comparision of the United States and Germany-, Deutscher Universitats-Verlag, Wiesbaden, Germany, 2006.

3- Bank of England, Venture capital, Quarterly Bulletin, December 1982. Sur le site : http://www.bankofengland.co.uk/ Consulté le : 28/01/2016 à $18: 00$.

4- Cherif Monder, Ingénierie financière et private equity, Revue Banque Edition, France, 2003.

5- Dorothée Rivaud Danset, Annick Vignes, Le capital-risque et ses deux marchés, Revue d'économie industrielle, Vol.107, $3^{\mathrm{e}}$ trimestre 2004.

6- Emmanuelle Dubocage, Dorothée Rivaud-Danset, Le Capital-risque, éditeur La Découverte, Paris, 2006.

7- Eric Stéphany, La relation capitale-risque / PME ; Fondements et pratiques, édition De Boeck Université, Belgique, 2003.

8- Gilles Mougenot, Tout savoir sur le capital investissement, $5^{\mathrm{e}}$ édition, Gualino éditeur, France, 2014.

9- Jarunee Wonglimpiyarat, The dynamic economic engine at Silicon Valley and US Government programmes in financing innovations, Technovation, n26, 2006.

10- Josée ST-PIERRE, La gestion financière des PME -Théories et pratiques-, Presses de l'Université du Québec, Canada, 2003.

11- Khelil abderrazek, Capital-Risque et financement des PME, Le colloque national: "PME et son rôle en développement", Université Kasdi Merbah, Laghouat, 8-9 avril 2002.

12- Mansoor Durrani and Grahame Boocock, Venture Capital,Islamic Finance and SMEs, PALGRAVE MACMILLAN, Great Britain, 2006. 
مساهمة شركات رأس المال المخاطر في تمويل المؤسسات الصغيرة والمتوسطة

حالة الولايات المتحدة الأمريكية في الفترة (1980-2015)

13- Marco Da Rin, Thomas F. Hellmann, Manju Puri, A survey of venture capital research, Working Paper 17523, National bureau of economic research, Cambridge, October 2011.

14- Patrice Geoffron, Une analyse du processus de structuration des industries du capital-risque, Revue internationale P.M.E. : économie et gestion de la petite et moyenne entreprise, Vol.4, n3, 1991.

15- Pierre Battini, Capital Risque : Mode d'emploi, Ed Organisation, $3^{\text {ème }}$ édition, Paris, 2001.

16- Shahin Firoozmand and all, State of SME Finance in the United States in 2015, TradeUp Capital Fund and Nextrade Group, LLC, U.S.A, March 2015.

1- https://www.sba.gov Consulté le : 11/01/2016 à 20 :30.

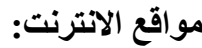

2- https://www.opic.gov/who-we-are/overview Consulté le: 21/01/2016 à 23:00.

3- www.nvca.org Consulté le : 28/01/2016 à 10:00.

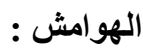

1- Alexander Haislip, Essentials of Venture Capital, Published by John Wiley \& Sons, Inc, New Jersey, U.S.A, 2011, P264.

2- Dorothée Rivaud Danset, Annick Vignes, Le capital-risque et ses deux marchés, Revue d'économie industrielle, Vol. 107, $3^{\mathrm{e}}$ trimestre 2004, P172.

3- Arnd Plagge, Public Policy for Venture Capital -A Comparision of the United States and Germany-, Deutscher Universitats-Verlag, Wiesbaden, Germany, 2006, P3.

4- Marco Da Rin, Thomas F. Hellmann, Manju Puri, A survey of venture capital research, Working Paper 17523, National bureau of economic research, Cambridge, October 2011, P3.

5- Mansoor Durrani and Grahame Boocock, Venture Capital,Islamic Finance and SMEs, PALGRAVE MACMILLAN, Great Britain, 2006, P36.

6- Eric Stéphany, La relation capitale-risque / PME ; Fondements et pratiques, édition De Boeck Université, Belgique, 2003, P11.

7- سامي عبد الباقي، دليل المستثمر لمفهوم ونثاط رأس المال المخاطر، سلسلة توعية المستثر

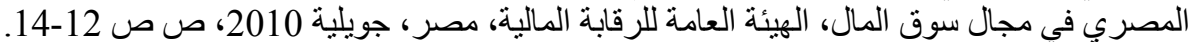

8- Josée ST-PIERRE, La gestion financière des PME -Théories et

pratiques-, Presses de 1'Université du Québec, Canada, 2003, P7.

9- Cherif Monder, Ingénierie financière et private equity, Revue Banque

Edition, France, 2003, p18. 
10- Shahin Firoozmand and all, State of SME Finance in the United States in 2015, TradeUp Capital Fund and Nextrade Group, LLC, U.S.A, March 2015, P3.

11- السيد أحمد عبد الخالق، المشروعات الصغيرة في ظل التحولات الاقتصادية المحلية والعالمية،

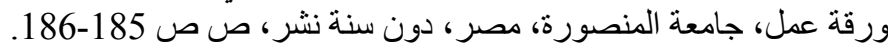

12- Khelil abderrazek, Capital-Risque et financement des PME, Le colloque national: "PME et son rôle en développement", Université Kasdi Merbah, Laghouat, 8-9 avril 2002, P37.

13- Patrice Geoffron, Une analyse du processus de structuration des industries du capital-risque, Revue internationale P.M.E. : économie et gestion de la petite et moyenne entreprise, Vol.4, n3, 1991, P98.

14- Khelil abderrazek, Op.Cit, P37.

15- Idem, P38.

16-Patrice Geoffron, Op.Cit, P98.

17- روينة عبد السميع، حجازي إسماعيل، تمويل المؤسسات الصغيرة والمتوسطة عن طريق شركات

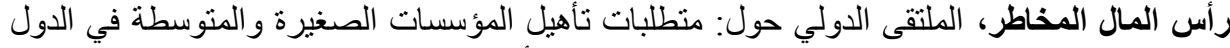

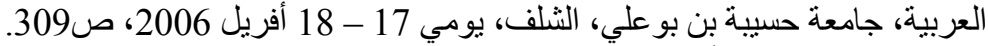

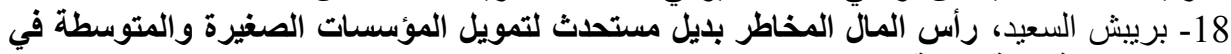

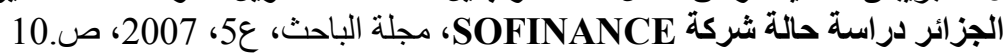

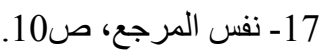

20- ARDC = American Research and Development Corporation.

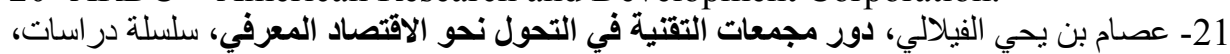

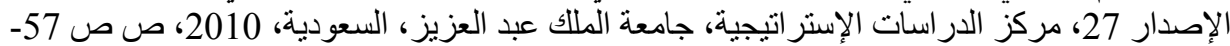

22-Bank of England, Venture capital, Quarterly Bulletin, December 1982,

P512. Sur le site : http://www.bankofengland.co.uk/ Consulté le : 28/01/2016 à

$18: 00$.

23- Gilles Mougenot, Tout savoir sur le capital investissement, $5^{\mathrm{e}}$ édition, Gualino éditeur, France, 2014, p145.

24- وزارة المالية (جمهورية مصر) ، تطبيق تجربة رأس المال المخاطر مع المشروعات الصغيرة

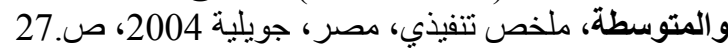

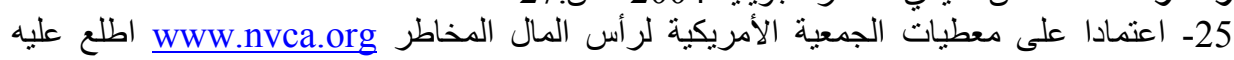

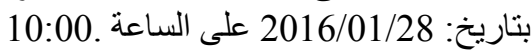

26- تقرير اللجنة الاقتصادية والاجتماعية لغربي آسيا (الإسكوا)، الموارد المالية الإلية ورأس المال المخاطر

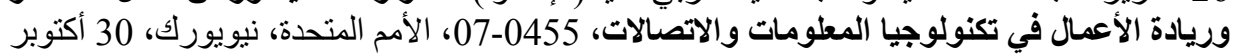

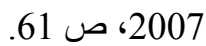

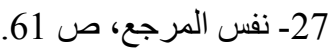

28- Gilles Mougenot, Op cit, P38.

29- Arnd Plagge, Public Policy for Venture Capital -A Comparision of the

United States and Germany-, Op cit, pp 33-34.

30- Report on SBICs, Small Business Investment Companies: Investment

Option for Banks, Office of the Comptroller of the Currency, Washington, 
September 2015, pp1-2. Sur le lien :

https://www.sba.gov/sites/default/files/article-files/insights-sbic.pdf Consulté le : 11/01/2016 à $20: 30$.

31- صافي حق الملكية الملموس (tangible net worth)= إجمالي أصول المؤسسة - الأصول غير الملموسة (بر اءات الاختر اع، حقوق التأليف و النشر ) - إجمالي الخصوم.

32- Arnd Plagge, Public Policy for Venture Capital -A Comparision of the United States and Germany-, Op cit, p35.

33- https://www.opic.gov/who-we-are/overview Consulté le: 21/01/2016 à 23:00.

34- Jarunee Wonglimpiyarat, The dynamic economic engine at Silicon Valley and US Government programmes in financing innovations, Op cit, P1085.

35- Pierre Battini, Capital Risque : Mode d'emploi, Ed Organisation, $3^{\text {ème }}$ édition, Paris, 2001 , p268.

36- Silicon Valley (تسمى أيضا هضبة السيلكون).

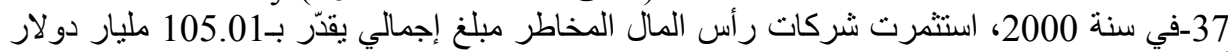

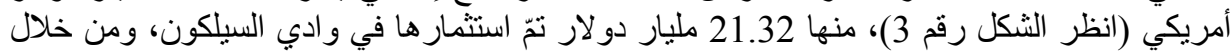

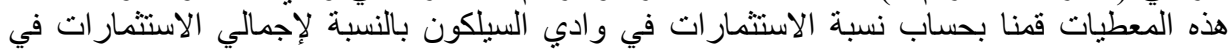

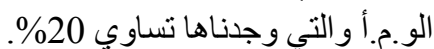

38- Emmanuelle Dubocage, Dorothée Rivaud-Danset, Le Capital-risque, éditeur La Découverte, Paris, 2006, pp 63-64.

39- الخروج الملكي: هو عبارة عن طريقة من الطرق التي تتبّعها شركات رأس المال المخاطر للتخلّي

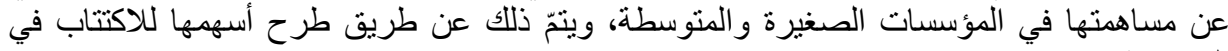

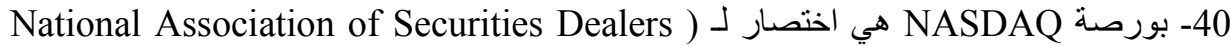
Automated Quotations system هيث أنثئت في سنة 1971، وتعتبر سوق مالي أمريكي

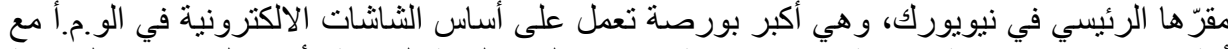

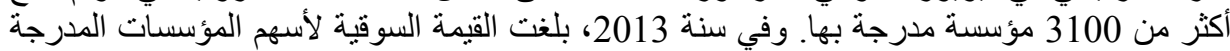
على مؤشر نازدالك حو الي 4582 مليار دو لار. 